\title{
The California Current System in relation to the Northeast Pacific Ocean circulation
}

\author{
Guillermo Auad $^{\mathrm{a}, \mathrm{b}, *}$, Dean Roemmich ${ }^{\mathrm{a}}$, John Gilson ${ }^{\mathrm{a}}$ \\ ${ }^{a}$ Scripps Institution of Oceanography, University of California, San Diego, United States \\ ${ }^{\mathrm{b}}$ Bureau of Ocean Energy Management, Herndon, VA, United States
}

\section{A R T I C L E I N F O}

Article history:

Received 17 December 2010

Received in revised form 14 September

2011

Accepted 18 September 2011

Available online 2 October 2011

\begin{abstract}
A B S T R A C T
The California Current System is described in its regional setting using two modern datasets. Argo provides a broadscale view of the entire eastern North Pacific Ocean for the period 2004-2010, and the High Resolution XBT Network includes transects from Honolulu to San Francisco (1991-2010) and to Los Angeles (20082010). Together these datasets describe a California Current of 500-800 km width extending along the coast from $43^{\circ} \mathrm{N}$ to $23^{\circ} \mathrm{N}$. The mean southward transport of the California Current is about 5 Sv off Central and Southern California, with about $2.5 \mathrm{~Sv}$ of northward flow on its inshore side. Interannual variations are $50 \%$ or more of the mean transports. The salinity minimum in the core of the California Current is supplied by the North Pacific Current and by freshwater from the northern continental shelf and modified by alongshore geostrophic and across-shore Ekman advection as well as eddy fluxes and air-sea exchange. The heat and freshwater content of the California Current vary in response to the fluctuating strength of the alongshore geostrophic flow. On its offshore side, the California Current is influenced by North Pacific Intermediate Waters at its deepest levels and by Eastern Subtropical Mode Waters on shallower density surfaces. In total, the sources of the California Current, its alongshore advection, and its strong interactions with the inshore upwelling region and the offshore gyre interior combine to make this a rich and diverse ecosystem. The present work reviews previous contributions to the regional oceanography, and uses the new datasets to paint a spatially and temporally more comprehensive description than was possible previously.
\end{abstract}

Published by Elsevier Ltd.

\section{Introduction}

The California Current (CC) System (CCS) includes poleward flowing waters near the coast (the California Undercurrent, the Davidson Current and the Southern California Eddy), e.g., Hickey (1979), having boundary-current scales and upwelling dynamics, and the much broader equatorward flowing CC located farther offshore. The latter is boundary-related in the sense of being forced by the equatorward deflection of the zonal atmospheric circulation as it encounters the North American continent. With that causality the CC's scale matches the broad atmospheric scale. The equatorward flow of the CC is swifter than the interior flow farther to the west because the negative wind stress curl is enhanced by the bending of the wind approaching the continent.

Although the CC can be regarded as an enhanced eastern interior circulation, several distinguishing characteristics make it an important element of the boundary current system. Its relatively strong geostrophic flow, Ekman transport, and eddy activity all interact to spread near-surface waters from the coastal zone rapidly offshore and alongshore. Beginning with the early descriptions of the CC by Tibby (1939), Sverdrup et al. (1942) and Reid et al. (1958), and to the more recent (Hickey, 1998), interest has focused

\footnotetext{
* Corresponding author at: Bureau of Ocean Energy Management, Herndon, VA, United States.

E-mail address: guillermo.auad@boem.gov (G. Auad).
}

on the ecosystem impacts of climate variability and change in this complex system (McGowan et al., 2003; Snyder et al., 2003; Di Lorenzo et al., 2005; Auad et al., 2006; Rykaczewski and Dunne, 2010). The CCS hosts many commercial species and an active food chain ranging from phytoplankton to marine mammals and sea birds (Sydeman et al., 2001). The physical aspects of the oceanic CCS (Auad et al., 1991; Batteen, 1997; Gan and Allen, 2002; Batteen et al., 2003; Marchesiello et al., 2003; Di Lorenzo et al., 2005; Capet et al., 2008a,b; Moore et al., 2009), their interactions with the overlying atmosphere (Seo et al., 2007) and with the local biology have been the focus of interdisciplinary observational (e.g., Roemmich and McGowan, 1995; Logerwell and Smith, 2001; McClatchie et al., 2008) and modeling studies (Powell et al., 2006; Goebel et al., 2010) while its ecosystems are highly dependent on the occurrence and duration of upwelling events taking place on the inshore flank of the CC (Bakun et al., 1973; Barton and Argote, 1980; Huyer, 1983; Schwing and Mendelssohn, 1997; Schwing et al., 2000; Chhak and Di Lorenzo, 2007; Chelton et al., 2007). Since the impacts of coastal upwelling are spread far offshore, it is necessary for the CCS study domain to be very broad. The primary dataset for physical/biological studies of the region is the 60-year time-series obtained by the California Co-Operative Fisheries Investigations (CalCOFI). However, due to resource constraints CalCOFI transects end a few hundred $\mathrm{km}$ from shore, near the core of the southward flow, and since the early 1980s they have included only waters from San Diego to just north of Point 
Conception. These data do not encompass the full domain and influence of the CCS.

In recent few years, importance of previously unexplored smaller scales, i.e., mesoscale and sub-mesoscale, has been recognized. This has been possible due to advances in modeling and observational arenas, with the advent of better models with increased spatial resolution and through new datasets including high resolution expendable bathythermograph data (Gilson et al., 1998), gliders (Davis et al., 2008), and high frequency radars (Emery et al., 2004). The new tools provide detailed information on the physical structure of small features such as squirts and filaments that are often associated with upwelling events. In turn, the small-scale features can affect the large scale oceanography of the CCS (Marchesiello and Estrade, 2009) since physical and biological properties carried offshore via upwelling-induced transport are mixed with CC waters by mesoscale and sub-mesoscale processes. Significant progress has been made over the past few years in understanding the role of small-scale features, especially in coupled ocean-atmosphere processes, e.g., Seo et al. (2007), Capet et al. (2008a,b,c), Maximenko et al. (2008), Centurioni et al. (2008), Dong et al. (2009), Levy et al. (2010).

The present study uses two modern datasets that complement the coastal CalCOFI data by spanning a broad regional domain in the eastern subtropical North Pacific. The region considered here $\left(20-50^{\circ} \mathrm{N}, 150-110^{\circ} \mathrm{W}\right)$ includes a part of the eastward North Pacific Current, its bifurcation at North America, the broad CC and a part of the interior farther offshore. The broad domain is chosen in order to describe the CC's physical boundaries, the three-dimensional structure of its mean geostrophic flow and its sources and influences. The first dataset is comprised of about 22,000 temperature/salinity profiles collected by the Argo Program in this domain since 2004. Argo presently has profiling floats spaced about $3^{\circ} \times 3^{\circ}$, each obtaining a profile every 10 days. While not resolving boundary currents or other narrow features, Argo is effective for describing the multi-year mean and seasonal variations of large-scale property distributions and geostrophic circulation. Second, the High Resolution XBT network includes two transects, each obtained quarterly. One of these, between Honolulu and San Francisco, began in 1991, while the other, between Honolulu and Los Angeles, began in 2008. Temperature profiles are collected at station spacing as fine as $10 \mathrm{~km}$ near the coast to resolve both the large-scale and mesoscale features occurring along these transects.

The present work begins with a basic description of the hydrography and circulation of the eastern subtropical North Pacific as seen in the Argo dataset, including its mean and seasonal variation. Within the broad domain, the physical boundaries of the $\mathrm{CC}$ are then located using three separate definitions based on salinity, current speed, and stability. These are roughly consistent with one another and with historical descriptions. One of the first estimations of the CC's offshore boundary was given by Reid et al. (1958) while Hickey (1979) placed the CC's core (maximum speed) at $270 \mathrm{~km}$ offshore from Point Conception. From the results published by Wyllie (1966), Strub and James (2000), Marchesiello et al. (2003) and Centurioni et al. (2008), the CC width is seen ranging between 500 and $900 \mathrm{~km}$ at different locations between San Francisco and mid Baja California.

Next, the description of the CCS is expanded to include both the alongshore and the offshore/onshore components of flow. In the surface layer, offshore Ekman velocity is comparable in magnitude and perpendicular to the alongshore geostrophic flow. Because the offshore component is large in relative terms, and further enhanced by an energetic eddy field, the CC and the coastal upwelling system interact with one another strongly, creating and maintaining a rich and varied marine habitat extending well offshore. In this respect, several studies of the CC have focused on the climate change-induced habitat quality variations of species found within the CC domain (Roemmich and McGowan, 1995; McGowan et al., 1998; Chavez et al., 2003; McGowan et al., 2003; Chan et al., 2008). Beneath the surface layer, the geostrophic flow has a net onshore component, feeding the upwelling system and bringing Eastern Subtropical Mode Water and North Pacific Intermediate Water into the CC domain from the west.

The presence of multiple spatial scales in the alongshore flow of the $\mathrm{CC}$ is addressed by comparing the Argo velocity field with that of the High Resolution XBT transects. The latter reveal multiple filaments of flow in the CC and the nearshore California Undercurrent that are not seen in the broadscale Argo data. Transport estimates for XBT and Argo are used to illustrate how these datasets can be combined in a consistent description of the CCS.

The study concludes with a preliminary look at interannual variability in the CC using both the Argo and High Resolution XBT data. The Argo time-series is short, but begins to show the largescale fluctuations in heat and freshwater content occurring in the CC. The longer time-series of geostrophic transport from the XBT data is used to investigate the CC transport variability. These datasets, plus other new (e.g. gliders and moorings) and ongoing (e.g. CalCOFI) measurement programs provide a wealth of information on variability of the Northeast Pacific circulation. The present work is aimed at describing the large-scale context and establishing a temporal baseline for the Argo era, and a starting point for more comprehensive physical and biological investigations of the CCS.

\section{Data}

The 7.5 year long (January 2004-June 2011) time-series of Argo float data (Roemmich and Gilson, 2009) was used for this study. Argo floats are distributed globally approximately every $3^{\circ}$ of latitude and longitude. Floats drift at $1000 \mathrm{~m}$ depth and every 10 days they collect a profile of temperature and salinity versus depth from about $2000 \mathrm{~m}$ to the sea surface. The Argo dataset was interpolated onto a monthly $1^{\circ} \times 1^{\circ}$ grid on 58 unevenly-spaced pressure levels using optimal interpolation methods (Roemmich and Gilson, 2009). Mean fields were calculated by averaging each month over all years from 2004 to (2010 or) 2011 and then averaging the 12 monthly means. While Argo is a broad-scale dataset which does not resolve mesoscale eddies and narrow features, it obtains sufficient profiles to reduce the eddy "noise" for mapping of the largescale ocean and its variability. The number of Argo profiles in $1^{\circ}$ spatial bins in the CCS domain is shown in Fig. 1 along with a time series of the total number of float profiles in the domain. Profiles continue to be added at a rate of about 300 per month in this region. In all there were 22,000 Argo profiles in the study domain (Fig. 1), and for estimates near the domain boundaries, additional profiles in adjacent regions were also used.

High resolution expendable bathythermograph (XBT) data (e.g., Gilson et al., 1998; Roemmich et al., 2001) were also included along line PX37 (San Francisco-Honolulu) and PX37S (Los Angeles-Honolulu). The XBT data were collected from container ships, with the first temperature profile obtained near the $100 \mathrm{~m}$ isobath off San Francisco or off Los Angeles, and subsequently with profile spacing as fine as $10 \mathrm{~km}$ near ocean boundaries and across swift currents. Spacing is as coarse as $50 \mathrm{~km}$ in the ocean interior. The XBT data are quality-controlled by comparison with adjacent profiles and with previous XBT data along the same tracks. A total of 75 XBT transects have been obtained along the PX37 line from 1991 to 2010 plus 10 along PX37S from 2008 to 2010 . The temperature data from each transect was interpolated onto a $0.1^{\circ}$ longitude grid every $10 \mathrm{~m}$ in the vertical. Along lines PX37 and PX37S, geostrophic velocity was calculated relative to $800 \mathrm{~m}$, using measured temperature together with salinity based on a T/S relation. For the pre-Argo period, the deviations from a historical $\mathrm{T} / \mathrm{S}$ relation were mapped using sparse 


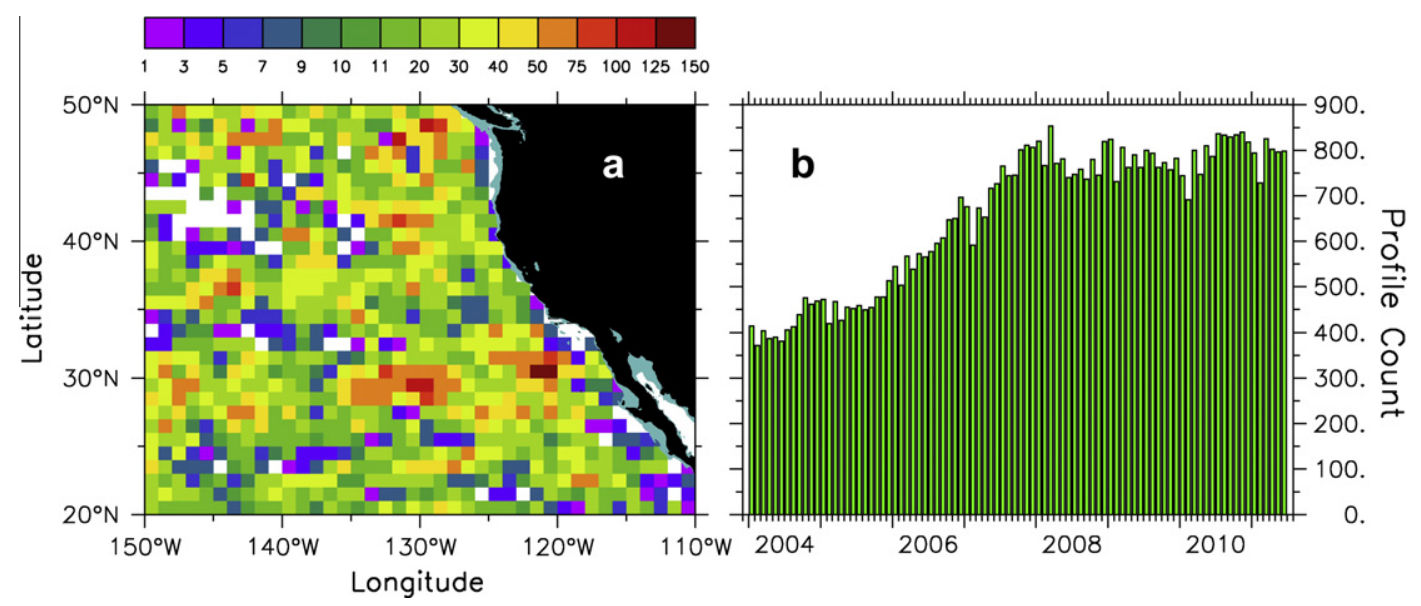

Fig. 1. (a) Number of Argo profiles in each $1^{\circ} \times 1^{\circ}$ box in the CCS domain, January 2004-June 2011. (b) Number of Argo profiles in the CCS domain in each month.

XCTD profiles collected during most of the XBT cruises (Gilson et al., 1998). For the recent period, the T/S relation was obtained by interpolating Argo data.

\section{Hydrography and geostrophic currents}

\subsection{Temperature}

The eastern North Pacific Ocean (NPO) is characterized by distinctive temperature fields in the nearshore and offshore domains (Reid et al., 1958) while also displaying distinctive vertical variations. The monotonic meridional gradient in mean sea surface temperature (Fig. 2, upper left panel), is a signature of direct atmospheric forcing, while at deeper levels (middle and right upper panels) the mass distribution associated with the subtropical gyre has a more direct role in defining the temperature field. Seasonally, the largest sea surface temperature differences (Fig. 2, left column), about $7^{\circ} \mathrm{C}$, are found in the north of the domain, with smaller seasonal differences of about $3{ }^{\circ} \mathrm{C}$ in the south. During summer (Fig. 2 bottom left) the signature of coastal upwelling is seen in the alongshore tilting of contours in the eastern part of the domain. A temperature minimum is observed along the coast of central California, with warmer surface waters both to the north and south. The seasonal differences rapidly decay with depth between 0 and $100 \mathrm{dbar}$ (middle column) and remain small between 100 and 200 dbar everywhere in the study area. At 100 and $200 \mathrm{dbar}$, most of the region is cooler in summer than in winter. In the annual mean temperature fields (upper panels), the advective effect of the CC in the surface layer (Lynn and Simpson, 1987) and its dynamical signature (geostrophic shear) in the subsurface layers are seen in the year-round southward displacement (or bending) of the isotherms on the eastern boundary. The overall seasonality and spatial thermal structure provided by the Argo temperature fields are consistent with previous descriptions of the eastern North Pacific thermal fields (e.g., Tibby, 1939; Reid et al., 1958; Lynn and Simpson, 1987; Hickey, 1998).

\subsection{Salinity}

The annual mean salinity field (Fig. 3 upper panels), also consistent with previous descriptions (e.g. Lynn, 1967), is dominated by the contrast between the salinity maximum of the gyre interior and the low salinity tongue that marks the core of the CC. The low salinity tongue is an advective feature extending alongshore, with increasing salinity along-current toward the southeast. It is seen down to $200 \mathrm{dbar}$, albeit with diminishing horizontal gradients. The direction of the easternmost isohalines at the surface and at 100 dbar is very different. While in the upper level they are directed nearly perpendicular to the coastline, they are nearly parallel to it at 100 dbar. This will be studied further in Section 5.

Unlike the temperature field, the spatial distribution of salinity does not show a pronounced or simple seasonal cycle at any depth (Fig. 3). As noted by Schneider et al. (2005) salinity variations in the CC area are mostly driven by internal (oceanic) rather than external (atmospheric) physics. On the sea surface, salinity off central California is slightly greater in summer than winter due to the higher salinity of upwelled waters. As with temperature, the seasonal variations in salinity are small at 100 and 200 dbar, suggesting that upwelled waters off California are extracted from shallow levels. This is consistent with the findings of Bograd et al. (2001) who found the bulk of upwelled waters to come from depths less than $150 \mathrm{~m}$, and Chhak and Di Lorenzo (2007) who reported upwelled waters from shallow depths $(\sim 100-200 \mathrm{~m})$ during warm phases of the Pacific Decadal Oscillation (PDO), i.e., the timeframe covered in this study.

A distinctive feature in sea surface salinity is seen off northern California and southern Oregon, where waters are fresher than 32 psu near the coast in summer. We will focus on this feature in the following sub-section on geostrophic flows.

\subsection{Geostrophic velocity}

Temperature (Fig. 2), salinity (Fig. 3) and pressure data from Argo were used to estimate steric height $(\mathrm{SH})$ and geostrophic velocity referenced to the $800 \mathrm{dbar}$ level. SH maps are shown in Fig. 4 as annual, winter, and summer means at three depths. In the annual mean maps, the tight spacing of sea surface steric height contours along the California coast, and the color shading indicating the flow speed, show that the CC has enhanced geostrophic velocity compared to the more sluggish gyre interior farther offshore. This tendency diminishes with depth, so a weak maximum in speed is seen at 100 dbar and at 200 dbar the shoreward enhancement of shear is no longer visible. At deeper levels (e.g. 500 dbar, not shown) the gyre interior is still seen but there is only weak shear in the CC. Flow speed on the sea surface is a maximum off Point Conception, where the alongshore current must accelerate around the cape. Seasonally, the flow speed increases in summer and the maximum shifts northward.

The largest seasonal change in steric height (Fig. 4) is located in the northeastern sector of the domain north of about $40^{\circ} \mathrm{N}$. There, the summer SH pattern suggests flow off the shelf toward the southwest. This is the same area where Fig. 3 exhibited sea 


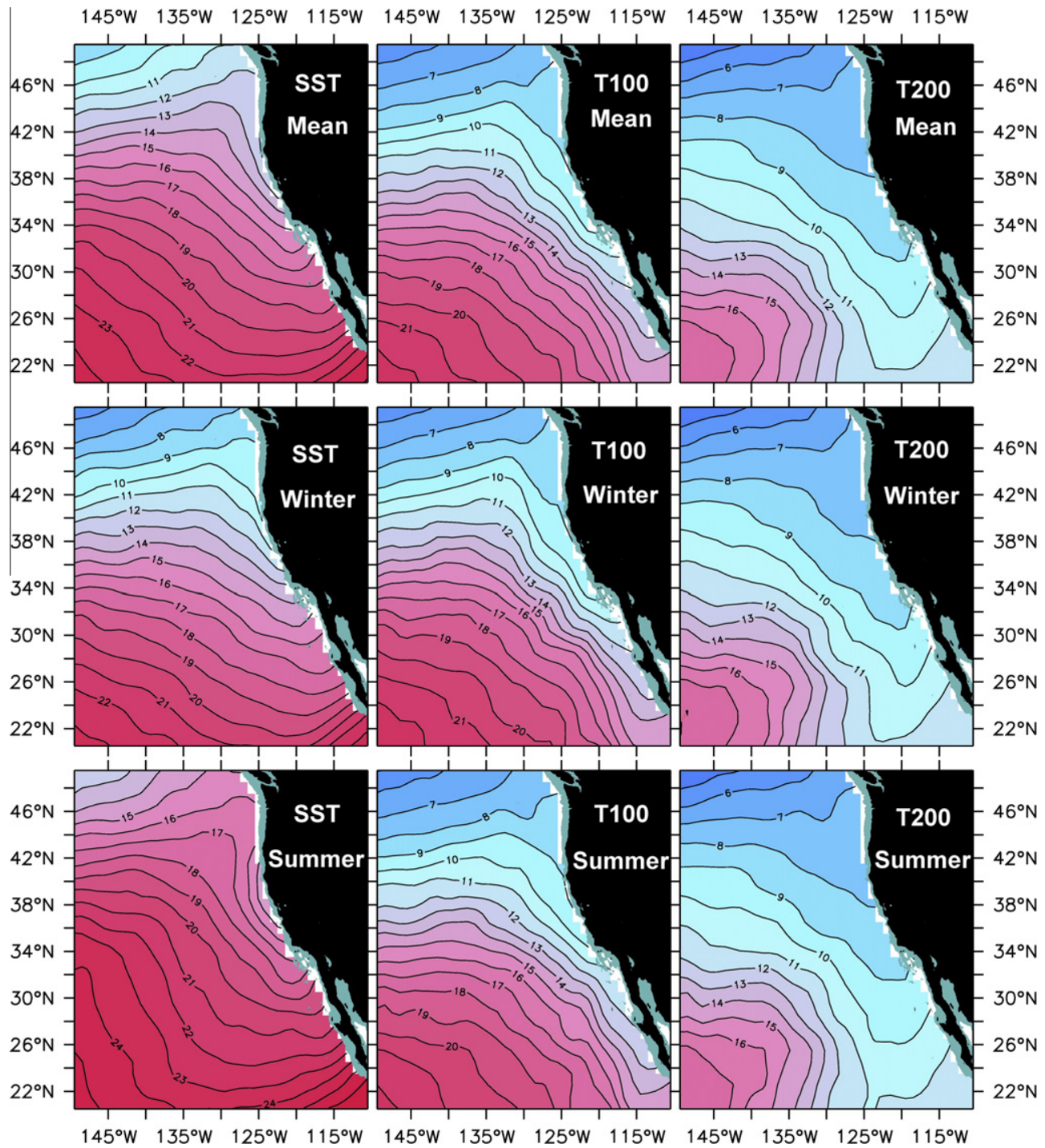

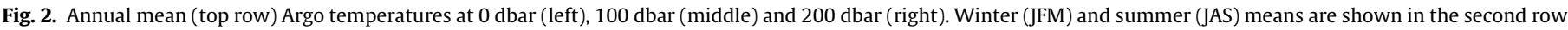
and third row respectively. Units are degrees Celsius while contour intervals $(\mathrm{CI})$ are $1{ }^{\circ} \mathrm{C}$

surface salinity fresher than $32 \mathrm{psu}$, consistent with a freshwater source on the shelf. Flow off the shelf toward the SW (Figs. 4 and 5 ) is also reported for this location during the summer season by Brink and Cowles (1991). Given the geographical location, shallow depth and seasonality of this low salinity area, it is plausibly the result of freshwater forcing originating in the rivers and streams of the northwest. The lack of near-coastal coverage by the Argo network prevents us from describing the inshore components of the CCS. Lynn and Simpson (1987) found that SH on the inshore side of the CC is lower in summer than winter, and higher on the offshore side (their Fig. 4a). The Argo sampling misses the inshore portion of the CCS, but shows the offshore SH increase and the merging of the $\mathrm{CC}$ into the subtropical gyre interior.

The summer pattern of sea surface $\mathrm{SH}$ is shown in greater detail in Fig. 5a, together with summer minus winter sea surface salinity difference (color shading). Fig. 5b shows the zonal geostrophic flow, averaged from 0 to $100 \mathrm{dbar}$, at the most shoreward grid points along the coast during summer, as a function of latitude. The bending of SH contours to parallel the coastline is evident, but one can also see the flow away from the shelf (about 4 dyn $\mathrm{cm}$ ) toward the southwest at $43^{\circ} \mathrm{N}$, with a seasonal fresh anomaly exceeding 0.4 psu. The $0-100$ dbar geostrophic flow is into the shelf (about 15 dyn $\mathrm{cm}$ increase in $\mathrm{SH}$ ) from Point Conception to the southern edge of our domain, providing the source waters for coastal upwelling. The large band of positive salinity difference centered off central California indicates the stronger upwelling of saltier subsurface waters and offshore Ekman transport in summer.

In the next section we estimate the horizontal and vertical boundaries of the CC. Locating the boundaries of the CC allows us to distinguish its properties and characteristics from that of contiguous regions. The CC is associated with particular fish species (e.g., Wilcox-Silver, 1975), some of them commercial, while their variability has been linked to atmospheric climatic sources (e.g., Hendy and Kennett, 2003; Kennett et al., 2003; Auad et al., 2003; McGowan et al., 1998). Knowing the boundaries of the CC will also facilitate comparisons among different epochs and datasets and will have the additional benefit of aiding in model tuning/validation and in model-model intercomparisons (e.g., Centurioni et al., 2008).

\section{The three dimensional structure of the California Current}

In order to better define the CC boundaries, three different definitions are suggested and compared with one another for similarity 


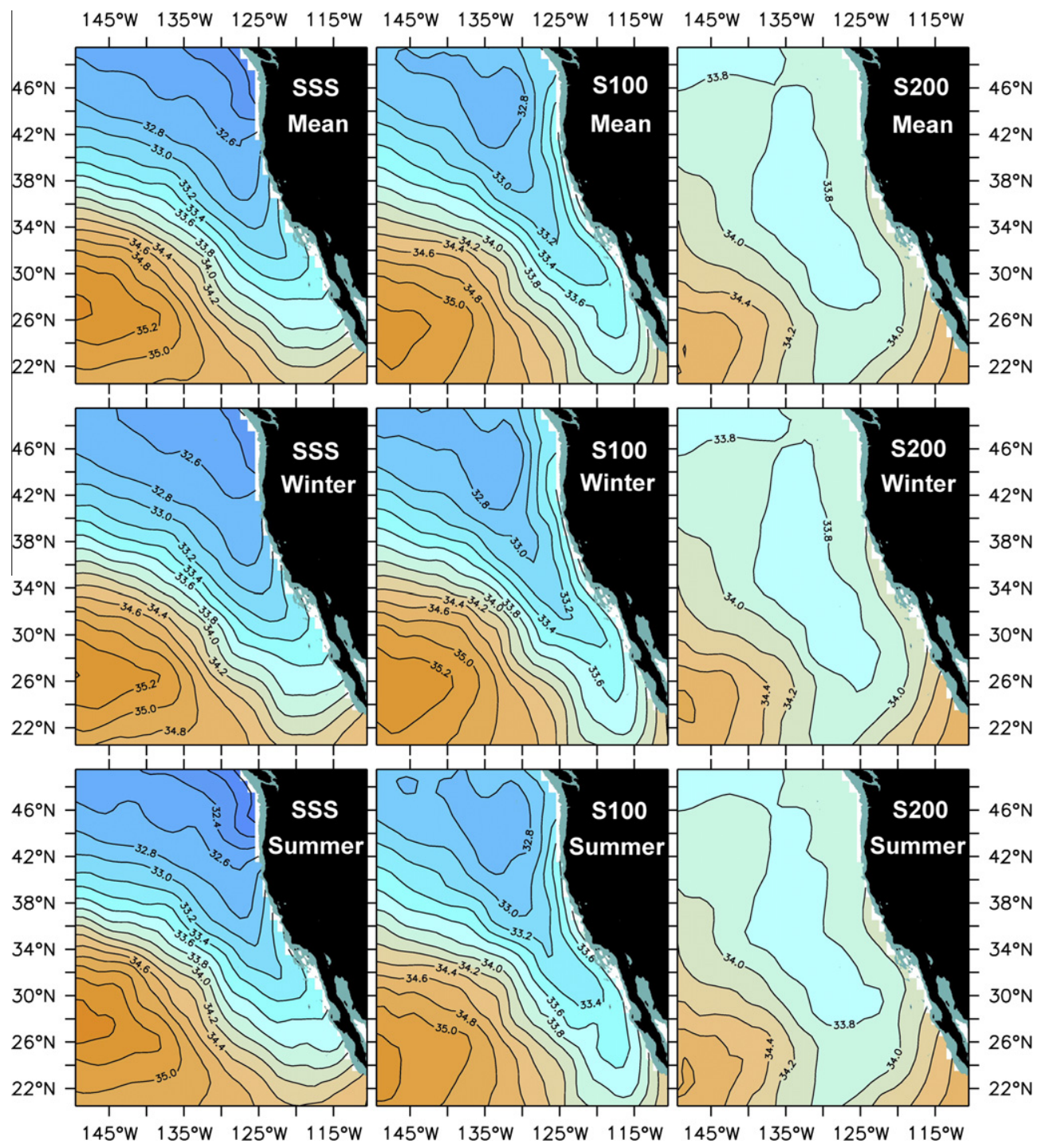

Fig. 3. As in Fig. 2 but for Argo salinities. Units are psu and the $\mathrm{CI}=0.2 \mathrm{psu}$.

and consistency. The CC might be identified either by its distinctive property distributions, by its elevated speed as compared to the more sluggish interior ocean circulation, or by its distinctive dynamical properties. Ocean current boundaries are ambiguous in the case of snapshots of eddy-rich regions, but are more clearly definable for mean fields. For this reason, and to extract more statistically reliable results, the present analysis uses multi-year mean fields. Seasonal variations in the boundaries, as defined below, are small. Of course, the spatial smoothing in the large-scale Argo dataset will have an impact on the estimated boundaries.

The first definition of CC boundaries is based on property distribution, and in particular on salinity. The low salinity core of the CC (Lynn, 1967) derives from its northern sources. The eastward-flowing North Pacific Current bifurcates at the North American coast at about $47^{\circ} \mathrm{N}$ (Fig. 4), carrying low salinity water southward into the CC (Fig. 3 upper panels) from regions having excess precipitation. The salinity minimum erodes as the current flows southward but remains as a distinctive feature. We define the boundary of the CC using salinity relative to the minimum salinity as a function of latitude. The CC boundary is defined by $S(x, y, z)-S_{\min }(y)=0.5$ psu. Here $S_{\min }$ can be on the sea surface or below, but a second condition is that the sea surface salinity is within 0.5 of $S_{\min }$. Fig. 6a shows the geographic extent and the depth of the $\mathrm{CC}$, based on these criteria. The relationship of the low salinity tongue of the $\mathrm{CC}$ to the alongshore geostrophic and across-shore ageostrophic velocity fields is further considered in the next section. The salinity field defines a CC of about $800 \mathrm{~km}$ width, extending from the bifurcation region in the north to Baja California, and with depth increasing offshore.

The second definition of the CC's boundaries is based on geostrophic velocity. From the Argo dataset, typical large-scale southward surface velocity in the gyre interior is $1-2 \mathrm{~cm} \mathrm{~s}^{-1}$. In order to be swifter than the interior, a minimum surface speed of $3 \mathrm{~cm} \mathrm{~s}^{-1}$ was required, with a southward component. Then, the current's depth was specified as the depth where the current speed decreases below $2 \mathrm{~cm} \mathrm{~s}^{-1}$. Through the thermal wind relationship, these criteria are equivalent to requiring a minimum value of the horizontal density gradient extending over a range of depths. Fig. 6b shows the geographic extent and depth of the CC based on these criteria. Here the maximum width, at about $34^{\circ} \mathrm{N}$, is similar to that in Fig. 6a, but the width decreases to the north and south so that the overall area is substantially less than in Fig. 6a. Depths are again greater on the offshore side, and of a similar range to Fig. 6a. The two definitions are compared in a vertical section; Fig. $6 \mathrm{~d}$, at $33^{\circ} \mathrm{N}$, where they define similar CC boundaries. The fact that the velocity field defines a more restricted domain overall illustrates the fact that, while the CC carries distinctive water mass characteristics, its flow field is not a lot stronger than that of the ocean interior. 

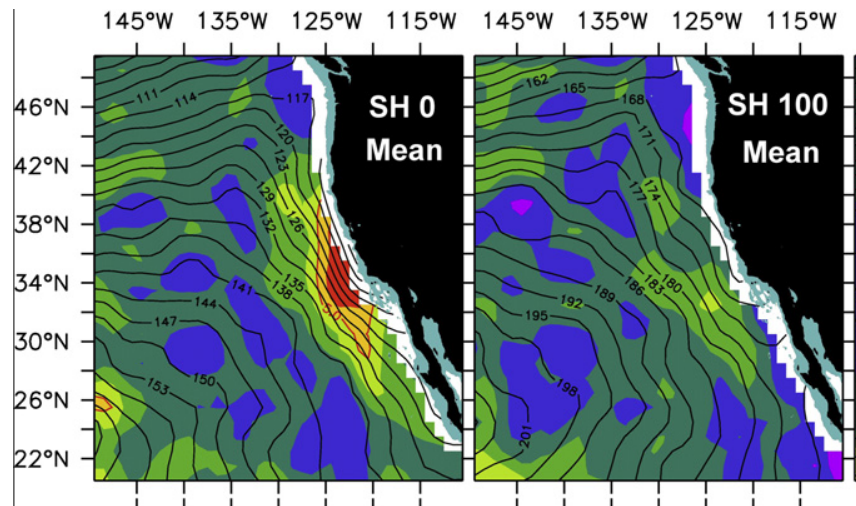

$145^{\circ} \mathrm{W} \quad 135^{\circ} \mathrm{W} \quad 125^{\circ} \mathrm{W} \quad 115^{\circ} \mathrm{W}$
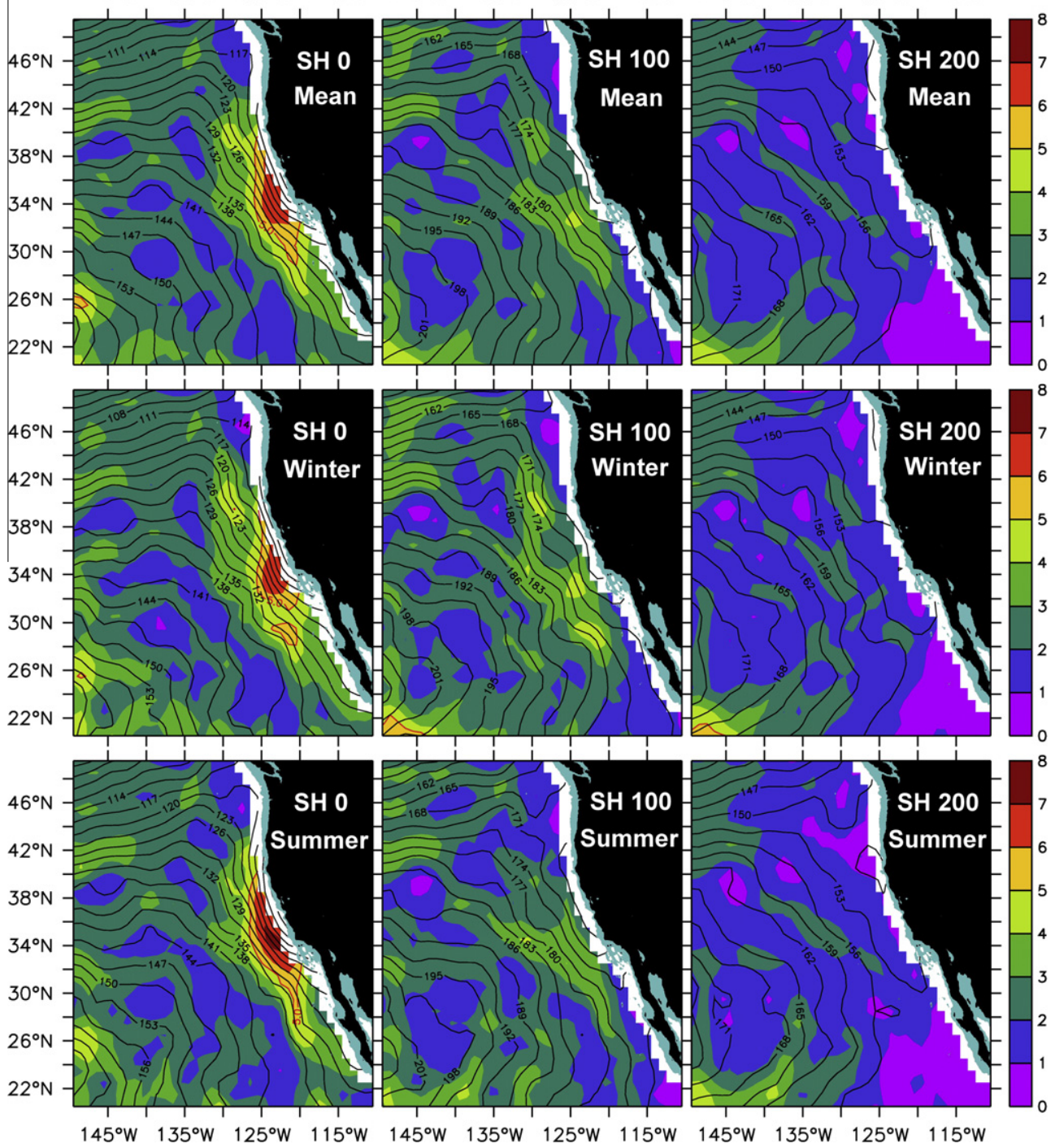

Fig. 4. As in Fig. 2 but for steric heights. The $\mathrm{CI}$ is 3 dynamic $\mathrm{cm}$. Color shading indicates speed (cm/s) of the geostrophic flow.

The third definition is based on dynamics, and specifically on a stability analysis of the CC mean flow. We solve the eigenvalue/ eigenvector problem associated with the quasi-geostrophic equations and vertical boundary conditions (flat bottom and rigid lid which translate into null vertical velocities at those boundaries) which are linearized about the mean flow (e.g., as in Kang et al., 1982; Lee and Niiler, 1987; Auad and Pares-Sierra, 1998):

$$
\begin{aligned}
& \left(\frac{\partial}{\partial t}+\bar{u} \frac{\partial}{\partial x}+\bar{v} \frac{\partial}{\partial y}\right)\left[\nabla^{2} \varphi+\frac{\partial}{\partial z}\left(\frac{f_{0}^{2}}{N^{2}} \frac{\partial \varphi}{\partial z}\right)\right] \\
& +\beta \frac{\partial \varphi}{\partial x}-\frac{\partial}{\partial z}\left(\frac{f_{0}^{2}}{N^{2}} \frac{\partial \bar{u}}{\partial z}\right) \frac{\partial \varphi}{\partial x}-\frac{\partial}{\partial z}\left(\frac{f_{0}^{2}}{N^{2}} \frac{\partial \bar{v}}{\partial z}\right) \frac{\partial \varphi}{\partial y}=A_{m} \nabla^{4} \varphi
\end{aligned}
$$

where $\bar{u}$ and $\bar{v}$ are the zonal and meridional components of the mean flow, $\varphi$ is the perturbation streamfunction, $f_{0}$ is the local Coriolis parameter, $N$ is buoyancy frequency and $\beta$ is the Earth's sphericity effect. On the right-hand side, $A_{m}$ is the Laplacian viscosity coefficient, for which a very small value of $30 \mathrm{~m}^{2} \mathrm{~s}^{-1}$ was used to facilitate convergence when solving the eigensystem problem.

The eigensystem problem is solved by sweeping the wavenumber space searching for the most unstable wave at every grid point. Growth rate is calculated and the CC defined as the region with growth rate greater than $0.03 /$ day, a value above that of the adjacent gyre interior. The sloping bottom effect and bottom friction were excluded from this calculation since both of them have a negligible impact on the growth rate amplitude (Auad and Pares-Sierra, 1998). The rationale behind this calculation lies in the fact that the oceans are naturally baroclinically unstable (and naturally barotropically stable) and thus locations exhibiting the largest vertical displacements of their isopycnals (i.e., maximum gravitational restoring force) will tend to both have large geostrophic speeds and be more unstable from the baroclinic standpoint.

Fig. 6c shows the extent of the CC based on the stability analysis. The highest growth rates tend to occur at or offshore of the current's velocity core. This could be explained by noting that given two water columns having the same isopycnal slope, the most unstable one will be the taller one. The spatial extent of the CC based on growth rate, Fig. 6c, is similar in width to that based on geostrophic velocity, Fig. 6b, and smaller than the salinity-based CC, Fig. 6a.

The CC by any definition is broad compared to, say, a western boundary current. It is a shallow, eddy-enhanced southward flow, with consistent descriptions provided by its property distributions, its velocity relative to the ocean interior, and its tendency to grow baroclinic waves. Any of the definitions might be considered as 

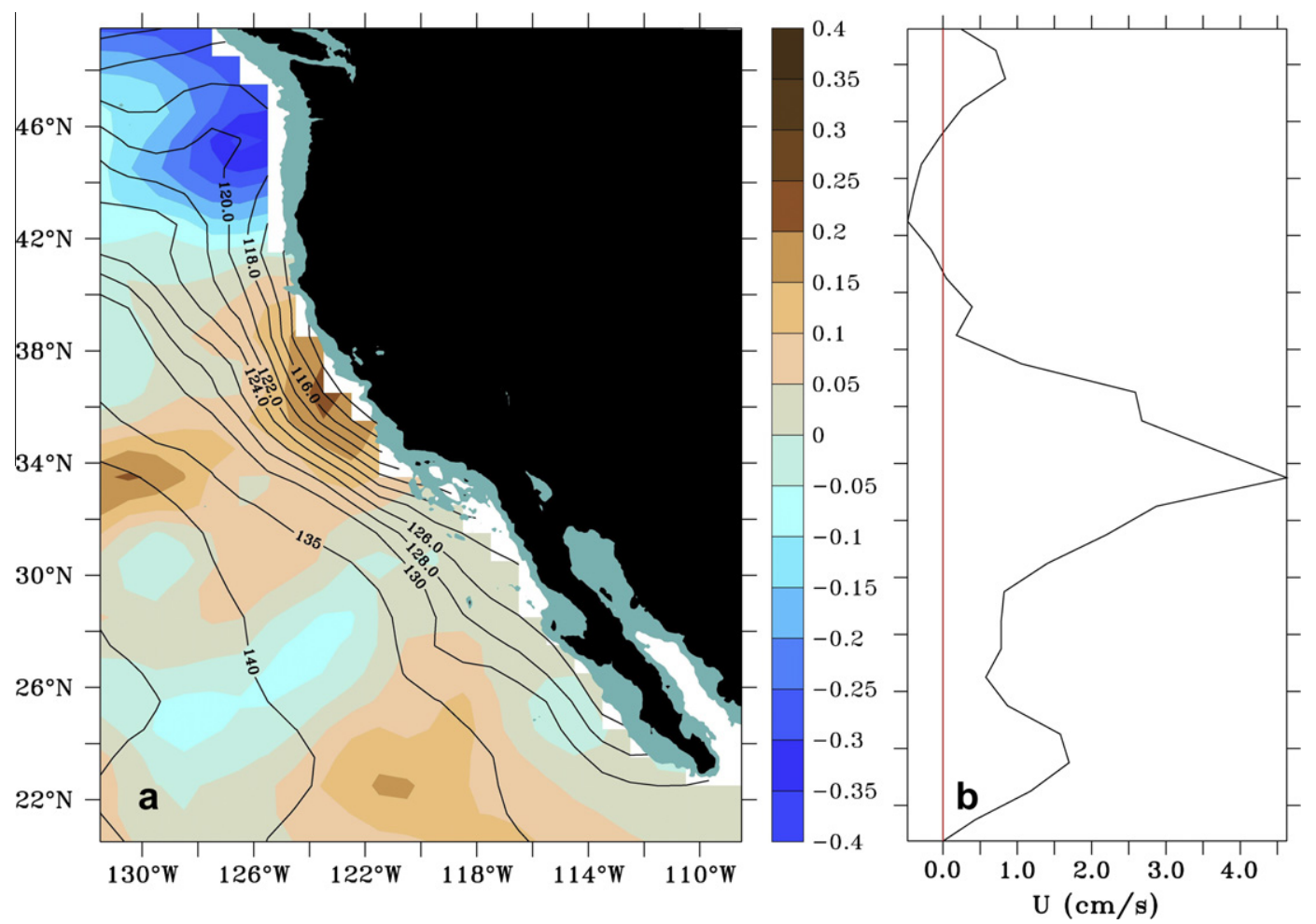

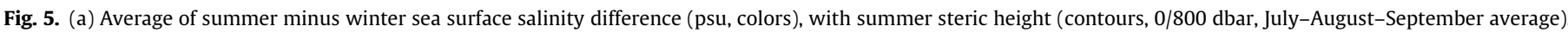
(b) Zonal geostrophic velocity (cm/s) 0-100 dbar and summer average, at shoreward-most grid points mapped from Argo data.

most appropriate for specific applications. Fig. 6 is also consistent with previous observational (Lynn and Simpson, 1987; Kelly et al., 1998; Centurioni et al., 2008) and modeling descriptions (Auad et al., 1991; Batteen 1997; Capet et al., 2008a) in that maximum eddy kinetic energy takes place at the core of the CC (maximum mean flow speed), at distances of $200-450 \mathrm{~km}$ offshore. The shallow nature of the flow seems unambiguous. Below 200300 dbar there is little in the property distributions or the geostrophic shear to distinguish the CC from the ocean interior. The width and structure of the CC are a different matter. Is the CC fundamentally very broad and sluggish, or is this an artifact of the broad-scale Argo coverage? This question is addressed in Section 7 below using the High Resolution XBT transects.

\section{The role of geostrophic and Ekman velocity in maintaining the salinity minimum of the CC}

Perhaps as important as defining the $\mathrm{CC}$ and its spatial domain is to describe its role in relation to the circulation of the overall CCS and the eastern North Pacific. The CC is located in the region of negative wind stress curl and downwelling, beginning about $100 \mathrm{~km}$ offshore. The upwelling region is farther inshore where the flow is poleward and the wind stress curl positive. However, exchanges between the inshore upwelling zone and the CC, including the mean Ekman transport as well as the eddy variability, spread newly upwelled waters far offshore. The low salinity tongue provides a useful proxy to illustrate the relative impacts of the Ekman across-shore and geostrophic alongshore advective contributions.

Fig. 7 shows the (Argo) geostrophic and (Ekman) ageostrophic horizontal advection terms in the mixed-layer mean salinity balance. The geostrophic velocity core, about $5 \mathrm{~cm} / \mathrm{s}$ alongshore, carries low salinity water southward, with a salinity gradient along the salinity tongue of about $1 \times 10^{-6} \mathrm{psu} \mathrm{m}^{-1}$ off central California. Thus $u \cdot \nabla S$ is about $5 \times 10^{-8}$ psu s$^{-1}$ for flow along the salinity minimum. The mixed-layer depth (MLD) is then estimated as the depth where density exceeds the surface density by $0.03 \mathrm{~kg} \mathrm{~m}^{-3}$. The MLD is calculated for each month of the gridded Argo dataset and averaged over all months. MLD increases offshore with typical values of about $20 \mathrm{dbar}$ in the low salinity tongue. We then calculate the equivalent amount of freshwater that, if added to the mixed layer per year, would cause a salinity decrease equal to the horizontal advection term, or about $1 \mathrm{~m} \mathrm{yr}^{-1}$ of freshwater based on the estimates above. Fig. 7a shows the geostrophic advection in the mixed layer, expressed as $\mathrm{mm} \mathrm{yr}^{-1}$ of freshwater, with the broad maximum due to the $\mathrm{CC}$ flowing along the fresh tongue. In Fig. 7b a similar calculation is made using the ageostrophic Ekman transport. This is calculated from NCEP/NCAR Reanalysis wind stress (Kalnay et al., 1996), and the Ekman transport is assumed to occur in the mixed layer, and $90^{\circ}$ to the right of the wind. In Fig. $7 \mathrm{~b}$ one can see that the Ekman velocity (Ekman transport divided by MLD) in the mixed layer is comparable in magnitude to the geostrophic velocity, and at right angles to it in the low salinity tongue. On the inshore side of the salinity minimum, the tendency is for Ekman transport to increase salinity as the relatively saline upwelled waters are pushed offshore. This tendency goes to zero at the salinity minimum and is reversed (to freshening) on the offshore side of the salinity minimum. Thus, along its core the low salinity tongue is maintained by the balance of freshwater advection, exchange by eddies, and the excess of evaporation-minusprecipitation.

\section{Water masses: the NPIW and the ESTMW}

The signatures of the North Pacific Intermediate Water (NPIW) and of the Eastern Subtropical Mode Water (ESTMW), and their relationship to the CCS, are studied in this section. The NPIW is defined as the salinity minimum in the $\sigma_{\theta}=26.6-27.0$ density range (Talley, 1993). In the western part of our domain the NPIW salinity minimum is found at $\sigma_{\theta}=26.7$ (e.g. Fig. 3 in Talley (1993)); farther 

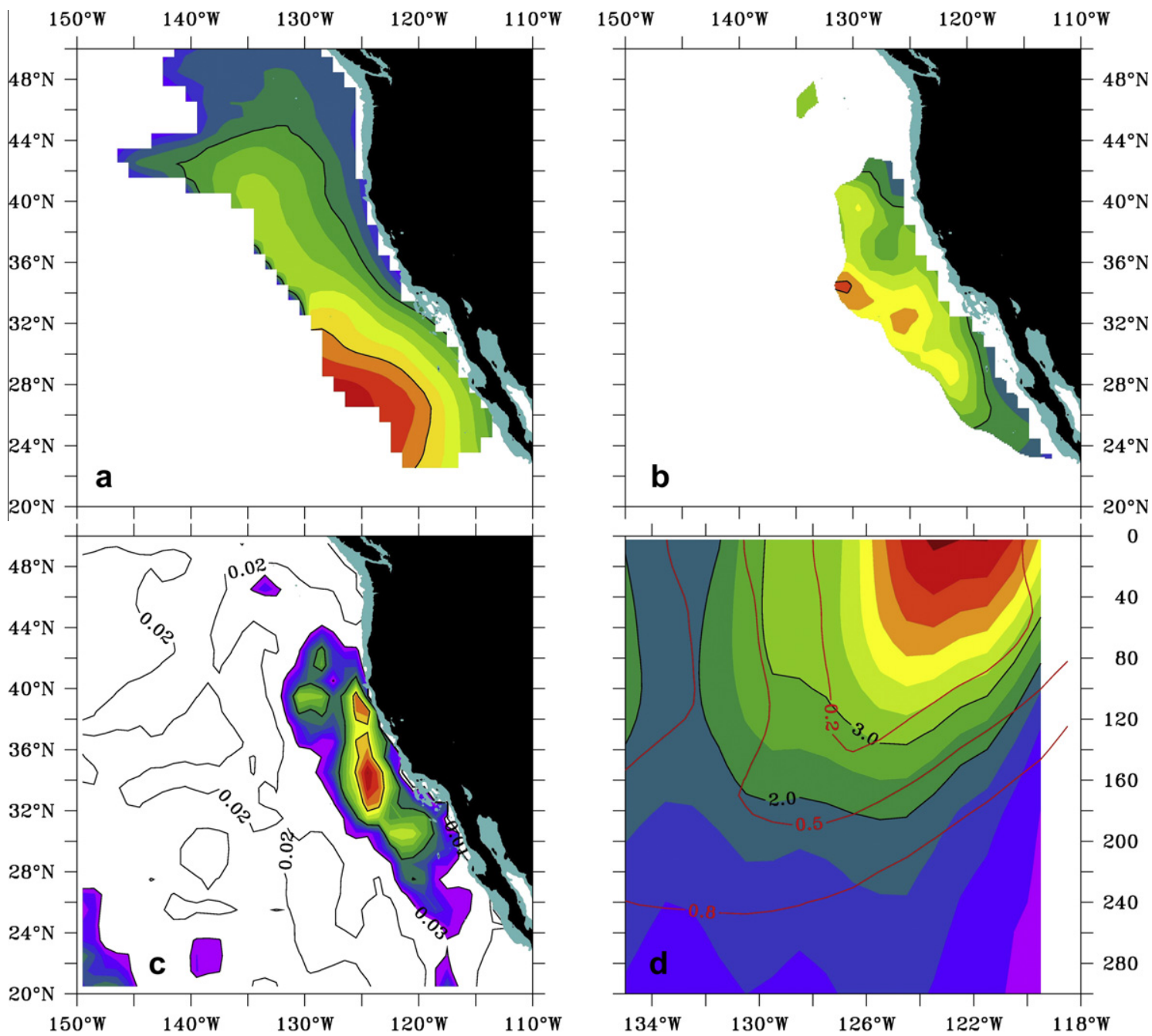

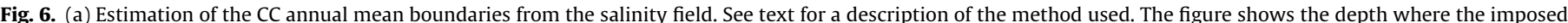

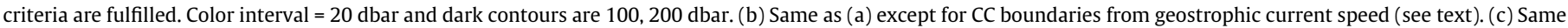

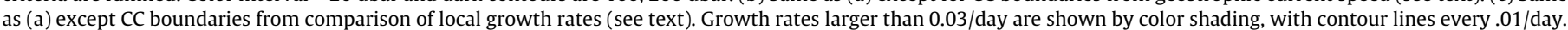

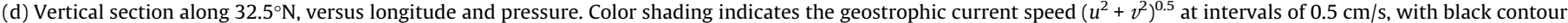
lines showing the 2 and $3 \mathrm{~cm} / \mathrm{s}$ levels. Red contour lines show the salinity difference with respect to the salinity minimum at this latitude.

east the density decreases and the salinity minimum merges into the surface salinity minimum. Fig. 8 shows the pressure, salinity, temperature, and acceleration potential (AP, an approximate streamfunction on an isopycnal surface, Montgomery, 1937; Reid, 1965; Buscaglia, 1971; Suga et al., 2008) for $\sigma_{\theta}=26.6$, that is, the top of the NPIW density range. Eastward flow into the region at about $44^{\circ} \mathrm{N}$ turns southeastward into the lower levels of the CC. Along this flow pathway shown in Fig. 8d, low gradients toward higher temperature and higher salinity are in contrast to the much stronger gradients along this isopycnal in the far southeast and north of the domain. Mixing of NPIW with CC water will be dominated by low frequencies and by timescales set by local eddy activity, especially by cold core eddies which are dominant in the CC area (Batteen et al., 2003). Off the Baja California coast and between $23^{\circ} \mathrm{N}$ and $27^{\circ} \mathrm{N}$ the stronger gradients in temperature and salinity fields separate fresh waters originating in the North Pacific and arriving from the north (Hendy and Kennett, 2003) from unventilated older saltier intermediate waters of tropical origin which are the last traces of Antarctic Intermediate Water (AAIW), e.g., Tsuchiya (1991), Hendy and Kennett (2003). This area of strong gradients is also characterized by strong meridional gradients in both potential vorticity (Talley, 1988) and in oxygen content between the deep (shallow) AAIW (NPIW) contributions. The confluence of these two water masses (Kennett et al., 2003) is a factor contributing to define long-term trends in oxygen concentration off the North American coast (e.g., Bograd et al., 2008; McClatchie et al., 2010).

ESTMW is formed from deep winter mixed layers in the density range $\sigma_{\theta}=24-25.4$ in the Northeast Pacific around $25-30^{\circ} \mathrm{N}$, $130-140^{\circ} \mathrm{W}$ (Hautala and Roemmich, 1998). The deep winter mixed layers result in a pool of low potential vorticity (PV) water that gradually restratifies during summer. The seasonal contrast (March-April compared to September-October) in PV on $\sigma_{\theta}=25$ is illustrated in Fig. 9a and b. PV is calculated as $Q=-\frac{f}{\rho_{0}} \frac{\partial \rho}{\partial z}$ where $\rho_{0}$ is density, $f$ is the Coriolis parameter and $z$ is the vertical coordinate. The bi-monthly averages in Fig. 9a and b are for all years, 2004-2011, and these patterns are consistent with the findings of Hautala and Roemmich (1998). They highlight the seasonal injection, near $30^{\circ} \mathrm{N}-140^{\circ} \mathrm{W}$, of low PV waters as a consequence of the quick ascent of the deep mixed layer base in late winter (spring transition). Then, closed PV contours start to develop once the forcing (injection of low PV waters) ceases. The ESTMW core defined by Hautala and Roemmich (1998) at $130-140^{\circ} \mathrm{W}$ is centered a few degrees farther west, near $140^{\circ} \mathrm{W}$, in Fig. 9a and b. Observations (Talley, 1988) and numerical evidence (Cox and Bryan, 1984; Capet et al., 2008c) support the qualitative and quantitative 

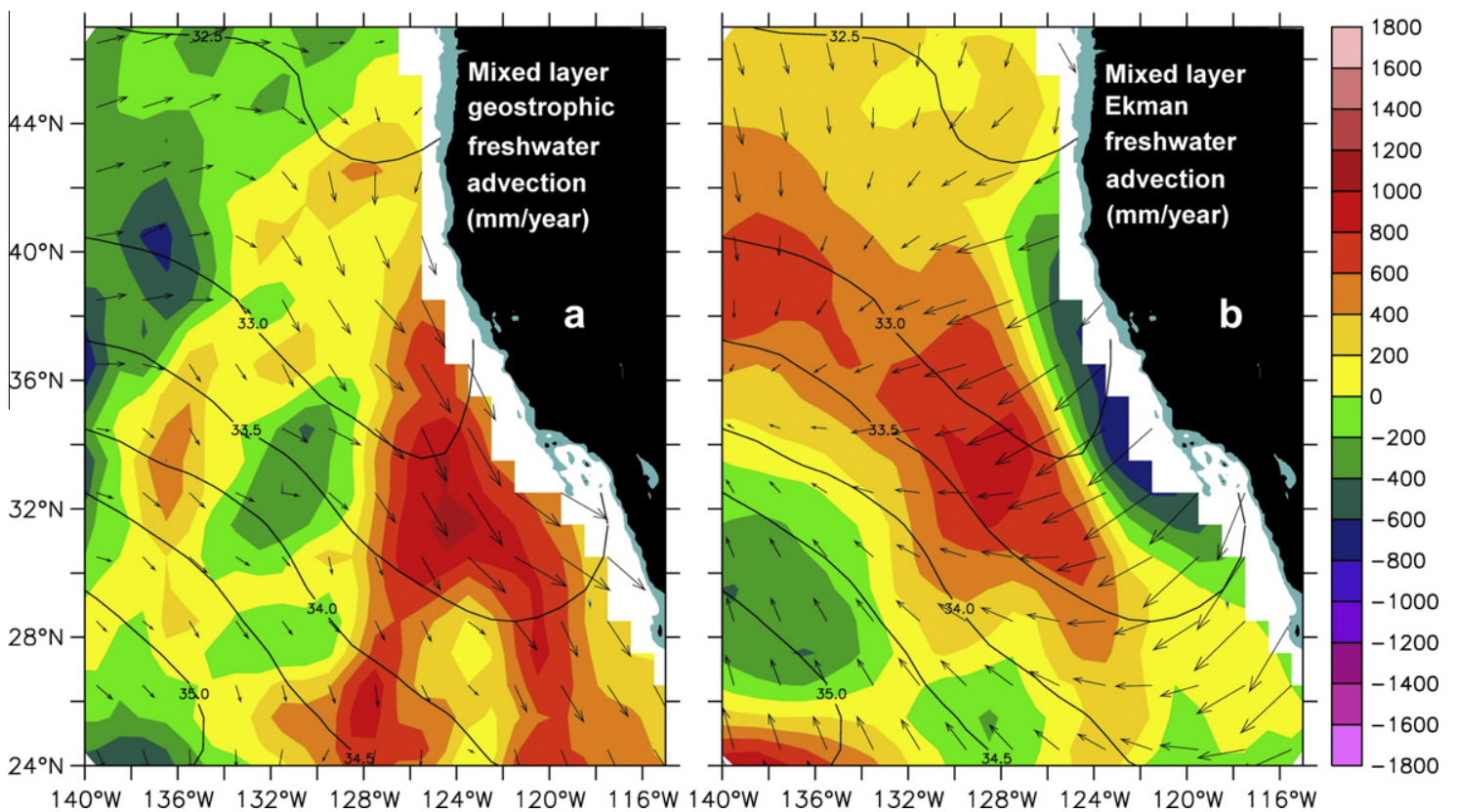

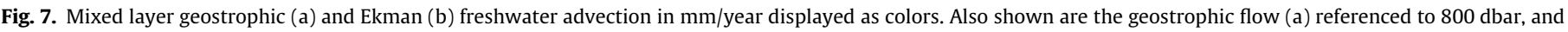
the Ekman velocity (from wind stress divided by the mixed layer depth, (b) and the sea surface salinity contours (CI = $0.2 \mathrm{psu}$ ).
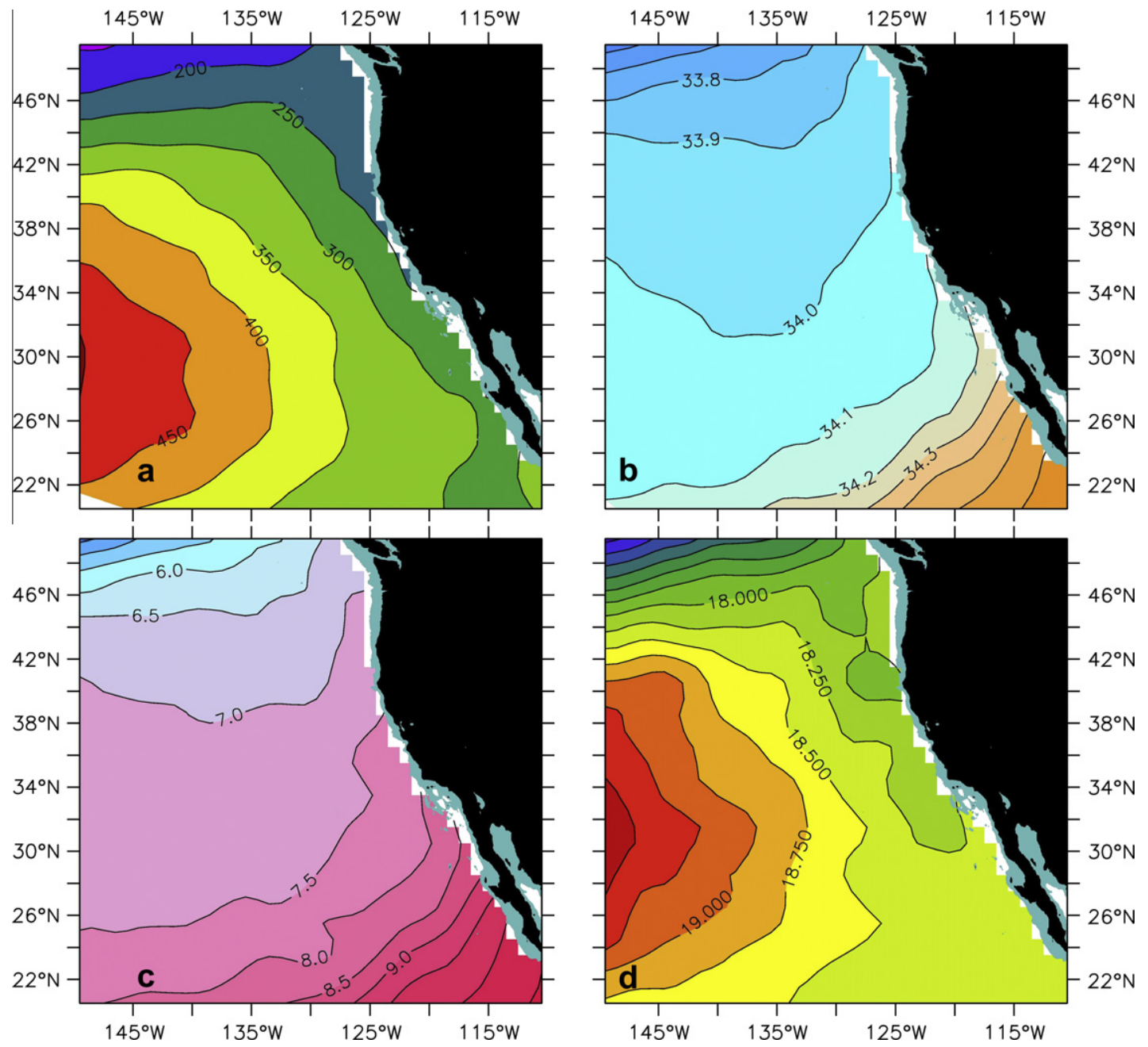

Fig. 8. Annual mean depth $((\mathrm{a}) \mathrm{Cl}=50 \mathrm{dbar})$, salinity $((\mathrm{b}) \mathrm{CI}=0.1 \mathrm{psu})$, temperature $\left((\mathrm{c}) \mathrm{CI}=1^{\circ} \mathrm{C}\right)$, and acceleration potential, relative to $2000 \mathrm{dbar}$, on $\sigma_{\theta}=26.6((\mathrm{~d})$ $\left.\mathrm{CI}=0.25 \mathrm{~m}^{2} \mathrm{~s}^{-2}\right)$. 


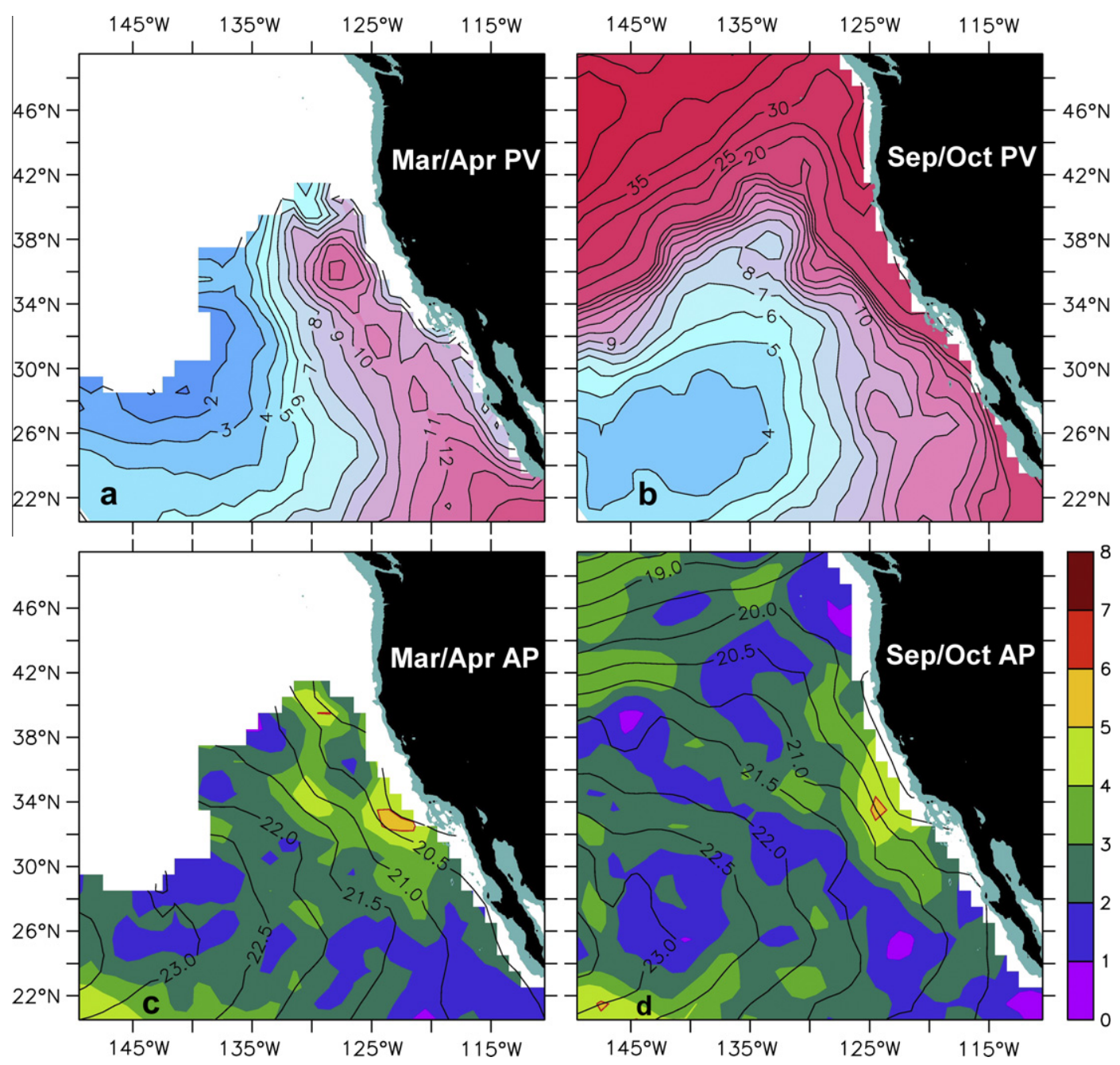

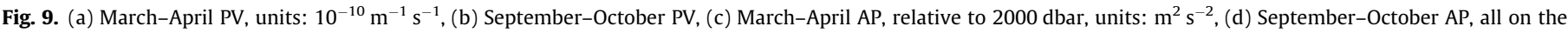
$\sigma_{\theta}=25$ isopycnal. The edge of the colored area marks the winter outcropping latitude.

features of the low PV corridor just discussed. Recently, Capet et al. (2008c) explained this entrainment of low potential waters in terms of the interaction of the wind stress with an oceanic front. Strong wind forcing, and an oceanic front are observed together during winter in the area at and nearby $40^{\circ} \mathrm{N}$ in the domain under study (e.g., Figs. 2 and 9). The fact that it shows highly non-zonal PV contours and that these are not parallel, in most areas, to those of the geostrophic streamfunction (below), underlines that time variations play an important role on this isopycnal. In addition, the large pool of low PV tends to decrease in size as the year progresses and re-stratification begins once the influx of low PV waters has stopped in early spring.

While seasonal changes in ESTMW properties such as stratification and PV are clear in the Argo data, circulation changes are more subtle. Fig. 9c and d shows the AP on the same isopycnal, $\sigma_{\theta}=25$, and for the same bi-monthly averages as Fig. 9 a and b. Color shading in these figures indicates the speed of the average geostrophic velocity on this isopycnal. In these, and in the other bi-monthly averages not shown, seasonal differences in the flow field are not clear. Recall that in the sea surface SH and geostrophic flow speed shown in Fig. 4, there was a summer maximum in the CC. Either this feature does not extend down to the ESTMW density, or perhaps the Argo coverage to date is marginal for detecting small seasonal changes in the circulation. Seasonality is considered further in the following section. What is clear is that the CCS has on its offshore side water masses of North Pacific origin in the near-surface layer (ESTMW) and below (NPIW), and that exchanges on the offshore side of the CC may be as important as those on the coastal side for modifying the characteristics of the CC.

\section{Low resolution (Argo) versus high resolution (XBT transects) geostrophic currents}

A view of the CCS that contrasts with the broadscale Argo dataset is provided by two repeating High Resolution XBT transects. Line PX37 runs from San Francisco to Honolulu and PX37S from Los Angeles to Honolulu. Fig. 10a and b shows the geostrophic velocity from transect PX37, relative to $800 \mathrm{~m}$, for two multi-year averaging periods, $1993-2003$ ( $N=46$ transects), and 2004-2010 (29 transects). The latter of these corresponds with the Argo era. A strong similarity of the mean velocity fields from the two periods is noted. Both periods show narrow poleward flow located just offshore of the shelf break off San Francisco, with a subsurface maximum greater than $10 \mathrm{~cm} / \mathrm{s}$. Then, farther to the west both show a series of three filaments of southward flow separated by northward reversals having subsurface maxima. These southward filaments are stronger and deeper than the interior flows farther offshore. Fig. 10c, geostrophic velocity relative to $800 \mathrm{dbar}$, was sampled from the gridded Argo dataset along the PX37 transect. As with the XBT data, Fig. 10c displays the velocity component normal to the transect. The lack of spatial resolution in Argo compared 


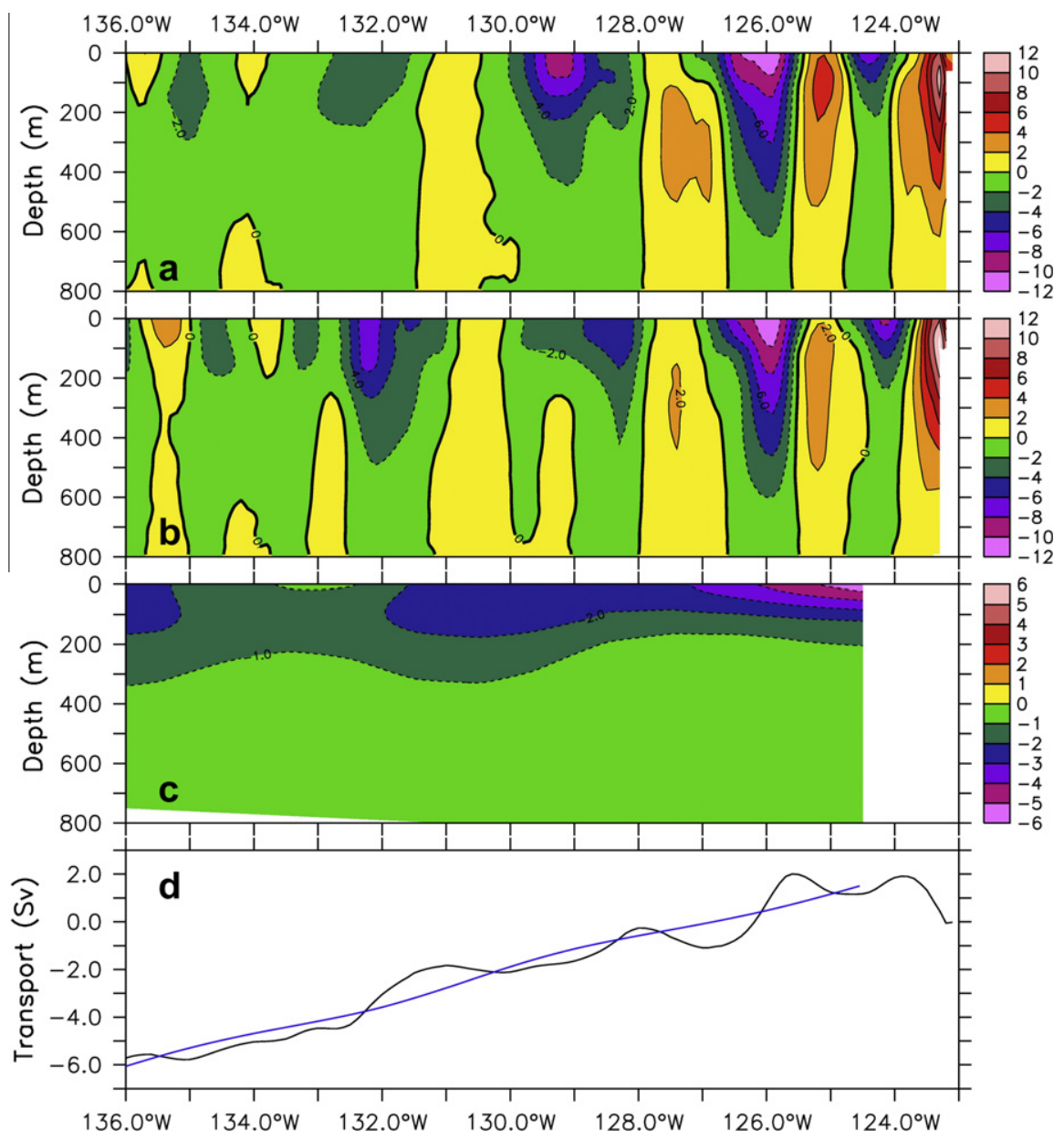

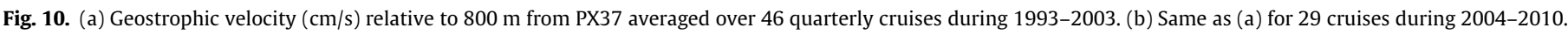

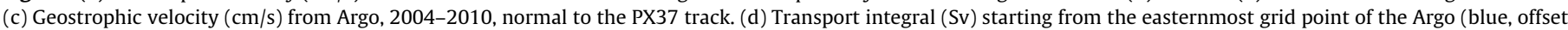
by $1.5 \mathrm{~Sv}$ ) and PX37 XBT (black) datasets.

to the XBT data is evident, including a lack of data to define the near-shore countercurrent. That the Argo velocity field is a spatially-smoothed version, consistent with the XBT data, is most evident in the transport integrals from both datasets, Fig. 10d. Both datasets show a California Current, with slightly enhanced, mostly southward velocity extending about $750 \mathrm{~km}$ offshore. The XBT data suggest that a better description of the $\mathrm{CC}$ might be as a broad region having multiple southward current filaments that are stronger than those in the ocean interior. This same characterization of the mean flow in the CC, as a series of distinct and persistent filaments, has also been made using historical datasets by Maximenko et al. (2008). Consistent with the stability analysis (Fig. 6c), the temperature variance and eddy kinetic energy (not shown) estimated from the XBT transects also have elevated levels in the broad CC relative to the ocean interior.

Mean transports ( $0-800 \mathrm{~m}$ relative to $800 \mathrm{~m}$ ) for the complete PX37 time-series are $2.3 \mathrm{~Sv} \pm 0.3$ for the poleward undercurrent $\left(125.6-123^{\circ} \mathrm{W}\right)$ and $5.0 \mathrm{~Sv} \pm 0.3$ for the equatorward CC (130$\left.125.6^{\circ} \mathrm{W}\right)$. The latter estimate is larger than historical estimates of the CC transport. Roemmich (1989) obtained 2.9 Sv for line 93 (off San Diego) of the CalCOFI grid using data from 1984 to 1987. For a different epoch (1984-1995), Bray et al. (1999) obtained $2 \mathrm{~Sv}$, also from CalCOFI data.

The large transport estimates from the PX37 data (Fig. 10d black line), relative to earlier ones from CalCOFI are due to two factors. First, CalCOFI sampling stops near the core of the CC and at
$500 \mathrm{~m}$, while we have integrated out to the mean edge of the CC and to $800 \mathrm{~m}$. Second, since the CC flow occurs in several narrow but recurring filaments (Fig. 10a and b) the transport estimate is sensitive to the horizontal scale. Here we selected transport integration limits to coincide with the edges of these filaments (125.6-130 $\mathrm{W}$ in Fig. 10d, but still consistent with the CC definitions of Fig. 6); this estimate is specific to the high resolution view of the CC. In contrast, the broad-scale view of transport, from Argo, is provided by the blue line in Fig. 10d. The slope of this transport integral, about $0.6 \mathrm{~m}^{2} \mathrm{~s}^{-1}$, is consistent with large-scale dynamics via the Sverdrup relation. That is, with the wind stress curl at this location being about $1 \times 10^{-7} \mathrm{~N} \mathrm{~m}^{-3}$, the Sverdrup transport estimate is about $0.5 \mathrm{~m}^{2} \mathrm{~s}^{-1}$ (and this meridional transport estimate would be adjusted upward by about $10 \%$ to account for the non-zonal $24^{\circ}$ slant of the PX37 track). Hence, the transport estimates are sensitive to both the domain of the $\mathrm{CC}$ and the sampling resolution.

Seasonal variations in the flow across line PX37 are shown in Fig. 11. For each season about 18 XBT transects are used from 1991 to 2010 to calculate seasonal averages of the geostrophic velocity. For the near-surface velocity, the standard error of the mean is about $4 \mathrm{~cm} / \mathrm{s}$ adjacent to the coast, decreasing westward to $2 \mathrm{~cm} / \mathrm{s}$ at $130^{\circ} \mathrm{W}$. Thus the spring velocity maximum in the southward CC filament closest to the coast $\left(124.3^{\circ} \mathrm{W}\right)$, about $18 \mathrm{~cm} / \mathrm{s}$, is a robust feature, as is northward summer maximum in the undercurrent adjacent to the coast, about $20 \mathrm{~cm} / \mathrm{s}$ at $100 \mathrm{~m}$. With 18 cruises per season the noise level is still 
substantial, but the line-based sampling mode is more efficient than the broadscale Argo array for determining the structure and statistics of properties on a vertical section.

We also estimated the transport of the $\mathrm{CC}$ from the shorter time series of XBT Line PX37S line (Los Angeles-Honolulu). Fig. 12 shows the location of PX37S in relation to the mean steric height field from Argo and to the location of CalCOFI Line 90, for which there is an extensive historical dataset (about 274 occupations) since 1950. For the 10 cruises along PX37S between late 2008 and late 2010, mean geostrophic transport (0-800 dbar) from the XBT data was $2.6 \mathrm{~Sv}$ northward between the coast and $121^{\circ} \mathrm{W}$, and $5.2 \mathrm{~Sv}$ southward between $121^{\circ} \mathrm{W}$ and $127^{\circ} \mathrm{W}$. As with the PX37 transport estimates off San Francisco, the integration endpoints were chosen as appropriate for the mean velocity field (Fig. 12) to mark the boundary between northward and southward transport $\left(121^{\circ} \mathrm{W}\right)$ and the offshore edge of the CC $\left(127^{\circ} \mathrm{W}\right)$. Similarly large and scale-dependent estimates of poleward transport were reported from glider data along Line 90 by Todd et al. (2011). Fig. 12 also shows mean transport across CalCOFI Line 90 cruises during the same 2-year time interval. Both the northward and southward flows are weaker in CalCOFI data because of the $500 \mathrm{~m}$ maximum depth of that dataset. Moreover, the coarser spatial resolution of CalCOFI compared to the XBT transects (upper panel of Fig. 12) results in less structure seen in the mean geostrophic velocity, and more of a "broad-scale" view as discussed above. Finally, Line 90 is not sampled beyond station 90.120 (Fig. 12, top) and in many historical cruises ends at station 90.80 or 90.100 . This results in the CC transport based on CalCOFI data being underestimated, as noted above. Overall, Fig. 12 illustrates how information from the XBT line PX37S, CalCOFI Line 90, and Argo can be synthesized to mitigate the spatial and temporal sampling limitations that each dataset has individually.

\section{Temporal variability of temperature, salinity, and kinetic energy in the California Current}

Time variability of large-scale property distributions in the CCS can be assessed on an area-averaged basis using the Argo dataset. Three indices were constructed to summarize the low frequency variability of the CC during the period 2004-2011. Volume averages of temperature, salinity, and kinetic energy per unit mass were computed for all years using both the salinity-based and speed-based definitions to define the time mean boundaries of the CC (Fig. 6a and b) Monthly and smoothed 12-month running means of these volume-averages are shown in Fig. 13. While the volumes over which these averages apply are quite different $5.0 \times 10^{14} \mathrm{~m}^{3}$ for the salinity-based definition (Fig. 6a) and $2.0 \times 10^{14} \mathrm{~m}^{3}$ for the speed-based definition (Fig. $6 \mathrm{~b}$ ) - the interannual variations in all three pairs of indices are similar (left-hand panels compared to right-hand panels of Fig. 13). Thus, there is little sensitivity of the large-scale interannual variations to the detailed choice of boundaries, though in general the amplitude of interannual variations is greater for the speed-based definition (Fig. 6b and right-hand panels of Fig. 13).

Temperature anomalies (Fig. 13a and b) show inter-annual variability that is smaller than the annual cycle but still substantial.

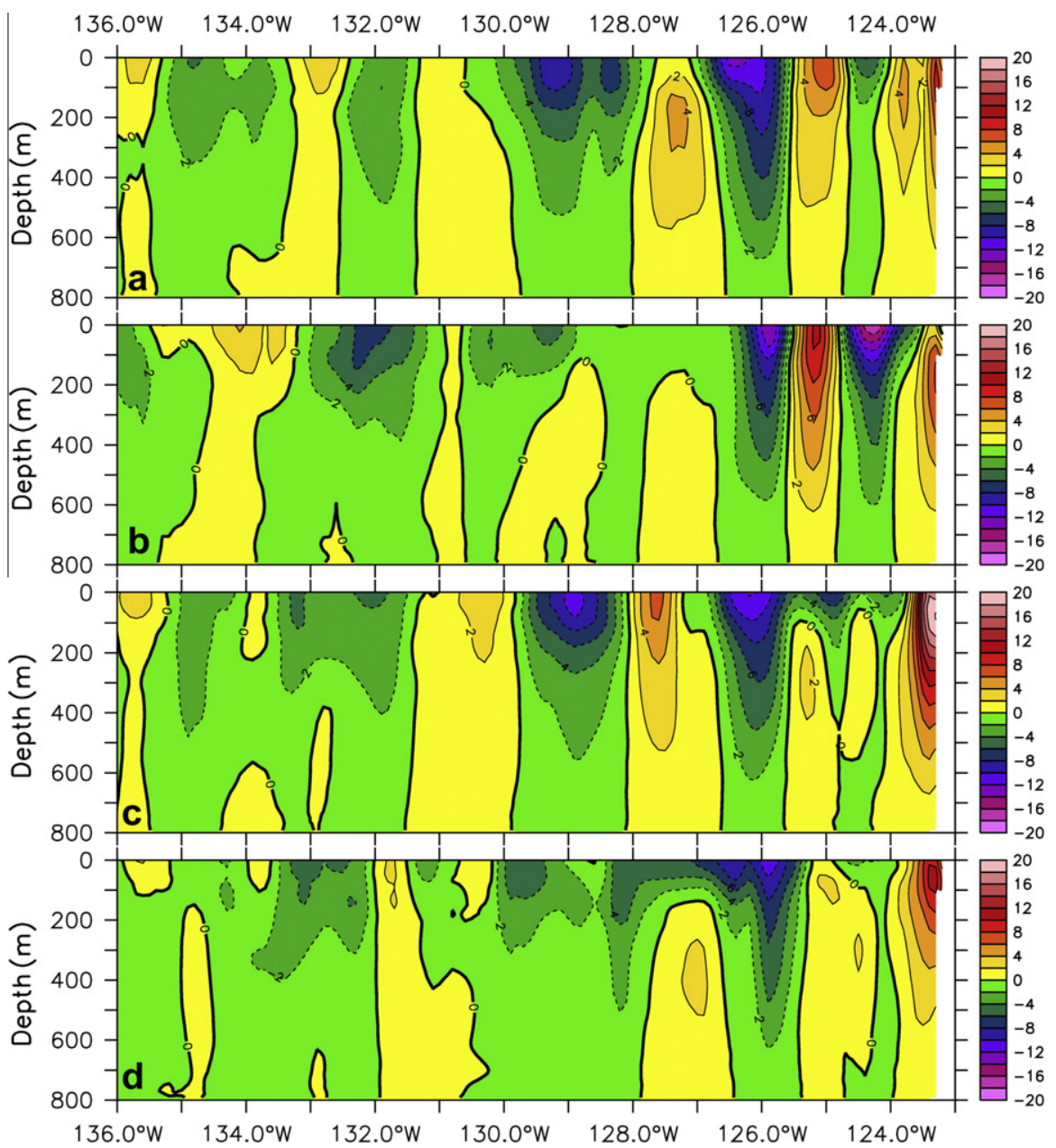

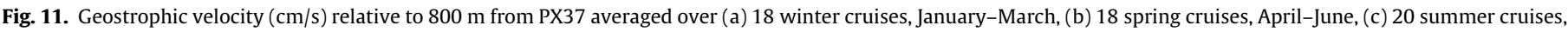
July-September, (d) 17 fall cruises, October-December. 

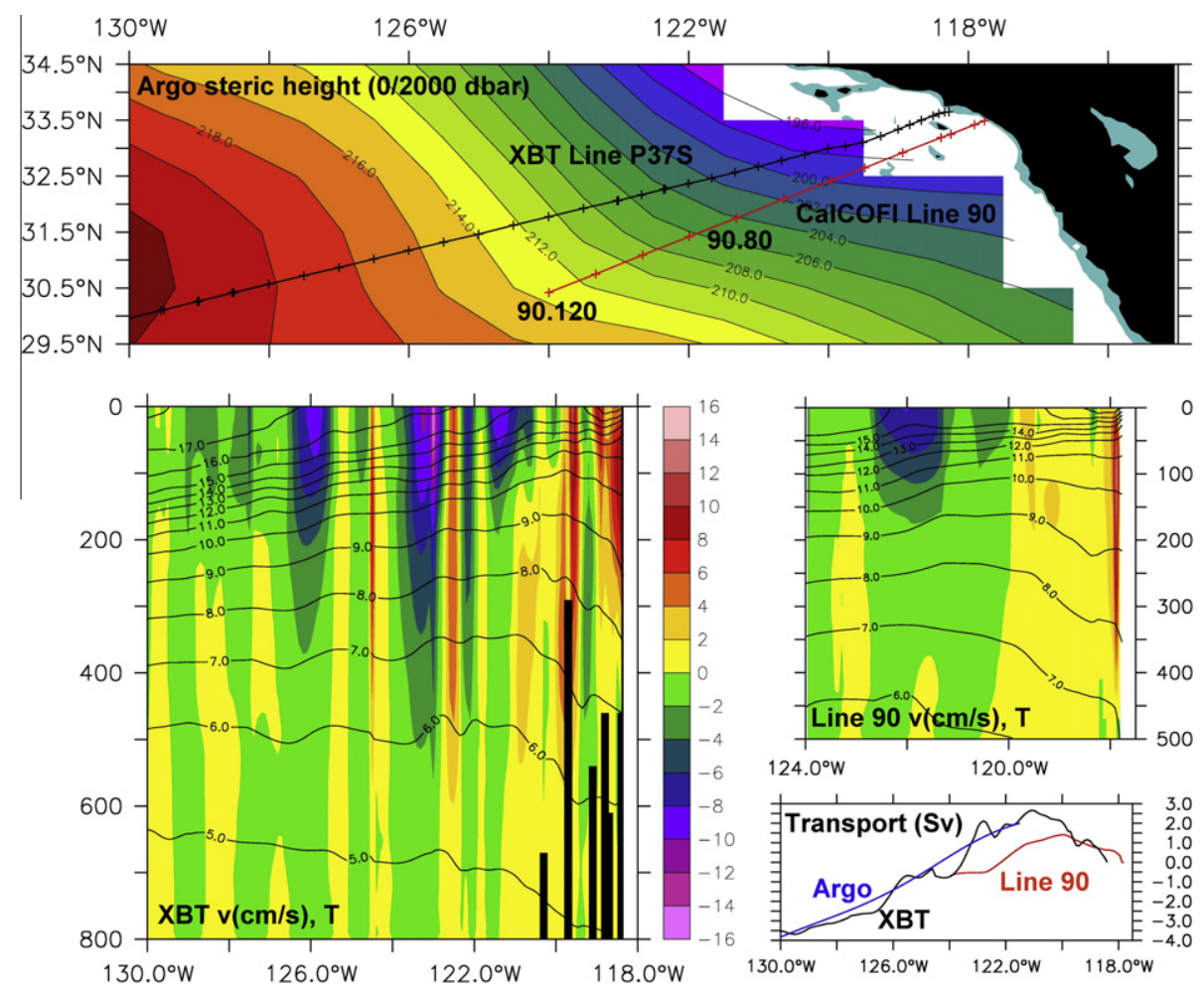

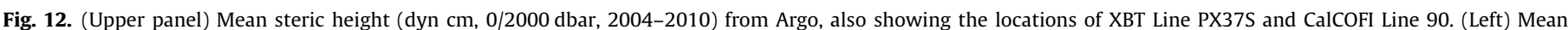

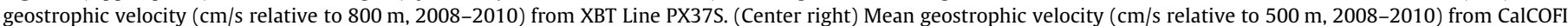

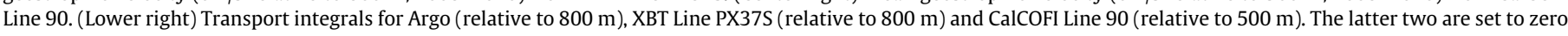
at their shoreward end. The Argo transport is integrated from a value of $2 \mathrm{~Sv}$ at $121^{\circ} \mathrm{W}$.

There is ENSO-related variability in the regional temperature and steric height (Roemmich and Gilson, 2011, their Fig. 1), and in Fig. 13 the warm anomaly during the 2009 El Nino and cooling in the following La Nina year are seen. ENSO effects are primarily confined to the near coastal ocean due to the poleward propagation of coastally trapped waves (Parés-Sierra and O'Brien, 1989).

The volume averaged salinity time series (Fig. $13 \mathrm{c}$ and d) is dominated by interannual variability, peaking in early 2007 and having significantly less high frequency content than the other two indices shown in Fig. 13. The unsmoothed salinity time series does not exhibit a marked annual cycle, consistent with Fig. 3 and with Schneider et al. (2005). As noted by them, salinity variations in the CCS area are primarily linked to large scale advective/diffusive fluctuations and disconnected from local atmospheric variability.

The volume-averaged kinetic energy time series (Fig. 13e and f) show interannual changes which are about $30 \%$ of the CC's overall mean kinetic energy. This index is also a proxy for eddy activity, as shown above through the linear stability analysis of the mean flow (Fig. 6c), from which we obtained the growth rates of baroclinically unstable planetary waves that can be sustained by the mass distribution in the CC-defined area (Fig. 6c).

A common denominator to all three indices in Fig. 13 is that low frequency interannual signals are present in all of them. The record is short, but visual comparison between the low frequency signals of the kinetic energy and volume-averaged salinity is also consistent with the findings of Schneider et al. (2005) in that the low kinetic energy values in the early years of the record would contribute to reduced advection and, increasing salinities, since low salinity waters are advected southward by the CC. That the phase relationships between temperature, salinity, and kinetic energy are more complicated than if controlled simply by alongshore advection, is clear from the different time series in Fig. 13. The minima and maxima in temperature and salinity occur at different times and the kinetic energy series has more structure than the other two. The mean annual cycle of kinetic energy (not shown) is consistent with Di Lorenzo (2003), with maximum kinetic energy values in the Argo data reached in late fall (November) and minimum values taking place in early summer (June).

For comparison with the large-scale time series of Fig. 13, the longer time series of the PX37 XBT data (1991-2010) was used to estimate volume transport variability for the poleward and equatorward constituents of the CCS. Noting the structure of the time mean velocity shown in Fig. 10a and b, transport $(0-800 \mathrm{~m}$ relative to $800 \mathrm{~m}$ ) was estimated for the poleward Undercurrent $\left(125.6-123^{\circ} \mathrm{W}\right)$ and for the equatorward CC $\left(130-125.6^{\circ} \mathrm{W}\right)$. These two time series, which are anti-correlated due to the meandering nature of the boundary between them, and their combined sum, are shown in Fig. 14. Both the CC transport and the combined sum show a southward maximum in 2003, then decreasing southward flow through 2006, and then increasing through 2008. These interannual fluctuations are roughly consistent with the area-averaged values described in Argo above - that is, increases in southward transport coincide with warming and freshening anomalies. The 2008 maximum in both the poleward Undercurrent and the equatorward CC (Fig. 14) coincides with the maximum in largescale kinetic energy (Fig. 13c). Using the same PX37 XBT transect plus another from Honolulu to Alaska (PX38) and a data assimilation model, Douglass et al. (2006) associated increases in the southward CC and ocean interior with increases in the eastward North Pacific Current.

The interannual variability seen in the CCS is likely caused by more than one forcing agent. In the light of the recent theoretical findings on the interaction between the subpolar and subtropical gyres (Zhong and Liu, 2009), we compared CCS net transport from line PX37 and the Aleutian Low Pressure Index (ALPI) (Beamish et al., 1997). The result (not shown) can account for some but not all of the variability seen in Fig. 14. There may be relationships 

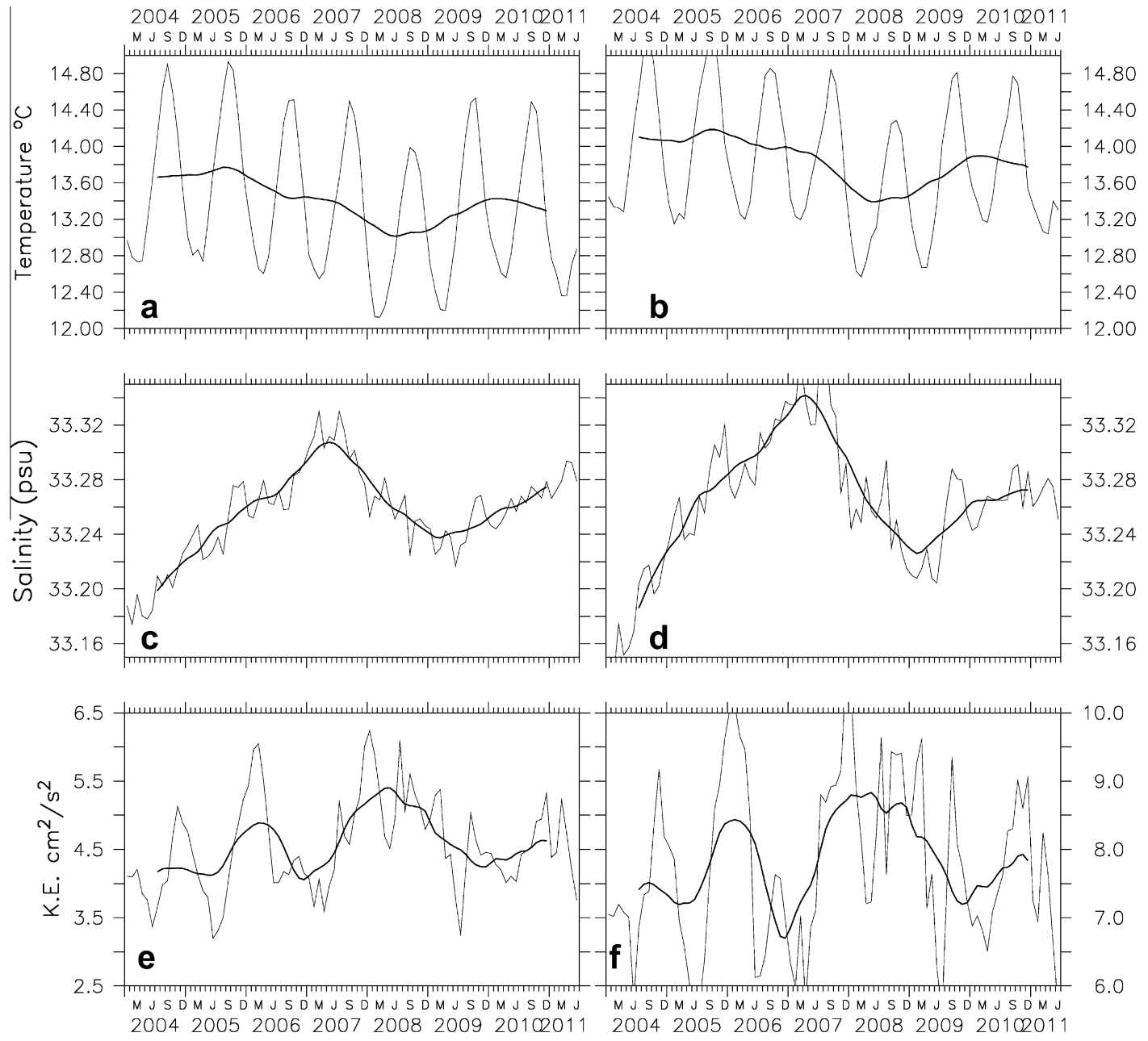

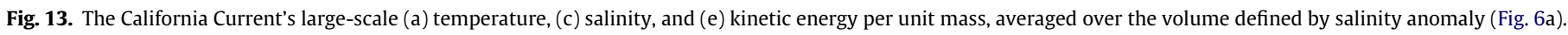
(b, d, and f) are the same except averaged over the volume defined by current speed (Fig. 6b).

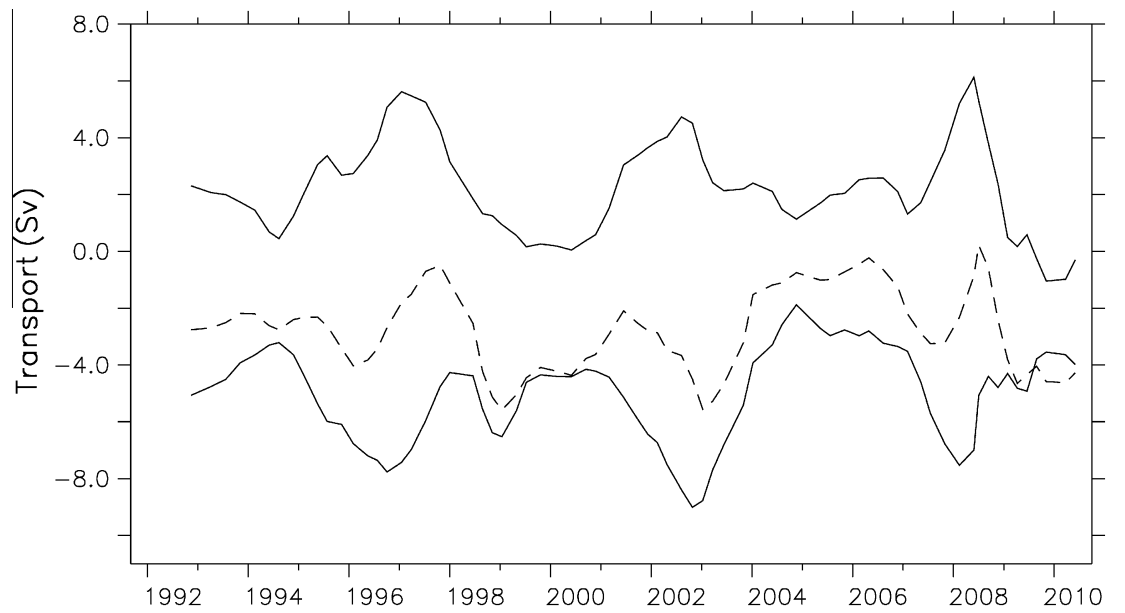

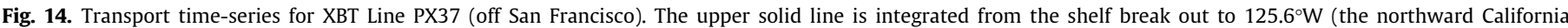

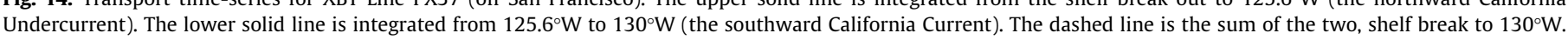

to high latitude atmospheric variations, as suggested by the ALPI, to tropical variability and possibly other factors. Additional work is needed to understand these relationships which, were preliminary considered in earlier studies by Miller and Schneider (2000), Auad (2003).

\section{Summary and conclusions}

Two new datasets (Argo and the High Resolution XBT lines PX37 and PX37S) were examined together with previous descriptions of the CCS and the Northeast Pacific Ocean circulation, in order to 
describe the regional context of the CCS and its three-dimensional structure. The global coverage of the Argo network allowed for a description of the entire region using a homogeneous dataset, as compared to earlier studies of the CCS using limited-area or mixed-instrument data sources. Of particular interest was the identification of southwestward flow at about $42^{\circ} \mathrm{N}$ in the easternmost waters covered by Argo. This surface-intensified current is most visible during summer, when it has the freshest surface waters seen anywhere in the domain $(S<32 \mathrm{psu})$. Its location, direction, and low salinity suggest origins in the high river runoff which characterizes these latitudes in spring and summer.

Using three different definitions applied to the Argo dataset (Fig. 6), the CCS occupies the area bounded by the $23^{\circ} \mathrm{N}$ and $43^{\circ} \mathrm{N}$ parallels and by a line which is approximately parallel to the coast and $500-800 \mathrm{~km}$ offshore. The shape, size, and orientation of the CCS depends both on the large-scale pattern of wind stress and on the slant of the California coastline. Depending on latitude, the location of the core of the CC (in large-scale terms, Fig. 4, or as the strongest of several permanent filaments in Fig. 10) is placed between 220 and $380 \mathrm{~km}$ from the coast, consistent with previous estimates. Maximum CC depths reach 150$250 \mathrm{~m}$ and coincide with the location of the fastest surface flow (i.e., the CC core). Of the three different definitions presented above (salinity-based, speed-based, and stability-based), the last two are most similar in their boundaries. The salinity-based method defines a somewhat broader CC extending farther to the north than the other two methods. Any of the definitions might be considered most appropriate depending on the specific application.

Comparison of geostrophic and Ekman surface velocity (Fig. 7) shows that they are comparable in magnitude and nearly perpendicular in direction. The low salinity tongue in the core of the CC is maintained by alongshore geostrophic advection balanced by excess evaporation, with Ekman velocity increasing salinity on the inshore side of the tongue and decreasing it on the offshore side. Newly upwelled surface waters and the low trophic-level biological activity in them are distributed both southward and offshore at comparable rates in the CC. This is important not only for biological studies (e.g., larvae transport), but also because it can potentially change the width of the CC as upwelling events alter the mass distribution. If upwelling events were to increase in intensity and/or number (Snyder et al., 2003; Auad et al., 2006), variations in the width of the CC could be monitored to obtain more accurate estimates of the biomass of different commercial species. These in turn are used to establish seasonal catch quotas for the fishing industry.

A new aspect arising from our analysis is that in addition to its relationship with the inshore upwelling zone of the CCS, the CC also has significant interactions on its offshore side and at different depths. At its deepest levels (around $250 \mathrm{~m}$ ) the CC receives NPIW contributions which mix together with saltier and warmer (spicier) waters originating in higher latitudes around $45^{\circ} \mathrm{N}$. At $100-150 \mathrm{~m}$, the $\mathrm{CC}$ also receives water through its western boundary which is characterized by the low potential vorticity signature of ESTMW. The influx of waters on the western side of the CC affects not only the water mass characteristics of the $\mathrm{CC}$, but may plausibly also impact the width and strength of the alongshore flow on a seasonal and interannual basis.

The CC mean flow structure obtained from the coarse resolution Argo array is consistent with that obtained from High Resolution XBT data along the PX37 (San Francisco-Honolulu) and PX37S (Los Angeles-Honolulu) transects. The datasets are complementary, with Argo covering the entire region on large-spatial scales, and the XBT data providing repeating transects at high spatial resolution. The XBT data show persistent small-scale filaments of flow and resolve the nearshore northward Undercurrent that is not resolved in the broadscale Argo profiles. Mean geostrophic transports for both PX37 and PX37S are about 5 Sv for the southward California Current, consistent with transport from Argo, and about $2.5 \mathrm{~Sv}$ northward for the Undercurrent.

Time variability in CC flow was also examined, using Argo to estimate changes in large-scale temperature, salinity, and kinetic energy anomalies, and XBT Line PX37 to relate those property variations to changes in the strength of the CC. A strong CC results in cooler, fresher surface waters. Adequate description of this complex region requires datasets that cannot only cover a larger region than historical measurements of the CCS, but that also resolve a wide range of spatial and temporal scales. We suggest that all of the subtropical gyre equatorward eastern "boundary" currents are similar to the CC in the sense of having broad spatial scales characteristic of the atmospheric circulation (rather than of oceanic boundary currents such as the Gulf Stream). Differences among different eastern "boundary" currents will lie partly in how the zonal westerlies are impacted by the differing coastal orography and local coastline orientation.

The role of the CC in the NPO circulation has several unresolved issues. Among these is the role of local and remote forcing in the interannual variability seen in Figs. 13 and 14. Targeted modeling experiments can be designated to dig deeper into this issue, which, has important implications in terms of the CC predictability and subsequent impact on coastal and near coastal ecosystems. Due to the lack of coverage of the coastal ocean by the Argo network we have not studied the California Undercurrent, except in the XBT transect. There is evidence (Mysak, 1977; Cornuelle et al., 2000 ) that the CC does receive westward inflows of mass, salt, temperature and momentum originated in offshore excursions (meanders) of the California Undercurrent especially when those meanders detach in the form of westward propagating eddies.

The Argo and high-resolution XBT views of the CCS presented in this study build on the extensive body of research in this region. However, while many of the pieces of the CCS and the eastern NPO have been described individually, the present work provides an integrated regional view that is original and facilitates a more robust and reliable analysis of three-dimensional features. The Argo and XBT datasets depict not only the CC, but its sources and sinks, its inshore boundary in the upwelling zone, its offshore interactions with the gyre interior, and the seasonal and interannual variations of all of these elements of the CCS. J.L. Reid has often characterized his global perspectives as including "the California Current and ALL of its tributaries" (Talley and Roemmich, 1991). The present work is a synthesis in that vein, beginning with the CC and set in the context of its Northeast Pacific "tributaries".

\section{Acknowledgements}

The Argo data used here were collected and are made freely available by the International Argo Program and by the national programs that contribute to it. The authors, GA while at SIO, were supported by the NOAA/SIO High Resolution XBT Program and the NOAA/SIO Consortium on the Ocean's Role in Climate (CORC) through NOAA Grant NA17RJ1231 (SIO-JIMO). GA appreciates the support of the Bureau of Ocean Energy Management during the writing and review stages of this article. We also thank two anonymous reviewers for their comments and suggestions which greatly contributed to improving the final version of this article. The statements, findings, conclusions, and recommendations herein are those of the authors and do not necessarily reflect the views of the National Oceanic and Atmospheric Administration or the Department of Commerce.

\section{References}

Auad, G., 2003. Interdecadal dynamics of the North Pacific Ocean. Journal of Physical Oceanography 33, 2483-2503. 
Auad, G., Pares-Sierra, A., 1998. Mean flow stability in the eastern North Pacific Ocean. Geofisica Internacional 37, 113-126.

Auad, G., Pares-Sierra, A., Vallis, G.K., 1991. Circulation and energetics of a model of the California Current System. Journal of Physical Oceanography 21, 15341552.

Auad, G., Kennett, J.P., Miller, A.J., 2003. North Pacific Intermediate Water response to a modern climate warming shift. Journal of Geophysical Research 108, 3349. doi:10.1029/2003JC001987.

Auad, G., Miller, A.J., DiLorenzo, E., 2006. Long-term forecast of oceanic conditions off California and their biological implications. Journal of Geophysical Research 111, C09008. doi:10.1029/2005JC003219.

Bakun, A., McLain, D., Mayo, F., 1973. The mean annual cycle of coastal upwelling off western North America as observed from surface measurements. Fishery Bulletin 72, 843-844.

Barton, E., Argote, M., 1980. Hydrographic variability in an upwelling area off northern Baja California in June 1976. Journal of Marine Research 38, 631-649.

Batteen, M., 1997. Wind-forced modeling studies of currents, meanders, and eddies in the California Current System. Journal of Geophysical Research 102, 9851010.

Batteen, M., Cipriano, N., Monroe, J., 2003. A large-scale seasonal modeling study of the California Current System. Journal of Oceanography 59, 545-562.

Beamish, R.J., Neville, C.E., Cass, A.J., 1997. Production of Fraser River sockeye salmon (Oncorhynchus nerka) in relation to decadal scale changes in the climate and the ocean. Canadian Journal of Fisheries and Aquatic Science 54, 543-554.

Bograd, S.J., Chereskin, T.K., Roemmich, D., 2001. Transport of mass, heat, salt, and nutrients in the southern California Current System: annual cycle and interannual variability. Journal of Geophysical Research 106, 9255-9275.

Bograd, S.J., Castro, C.G., Di Lorenzo, E., Palacios, D.M., Bailey, H., Gilly, W., Chavez, F.P., 2008. Oxygen declines and the shoaling of the hypoxic boundary in the California Current. Geophysical Research Letters 35, L12607. doi:10.1029/ 2008GL034185.

Bray, N., Keyes, A., Morawitz, W., 1999. The California Current system in the Southern California Bight and the Santa Barbara Channel. Journal of Geophysical Research 104, 7695-7714.

Brink, K.H., Cowles, T.J., 1991. The coastal transition zone program. Journal of Geophysical Research 96 (14), 637-14,647. doi:10.1029/91JC01206.

Buscaglia, J., 1971. On the circulation of the intermediate water in the southerwestern Atlantic Ocean. Journal of Marine Research 29, 245-255.

Capet, X., McWilliams, J.C., Molemaker, M.J., Shchepetkin, A.F., 2008a. Mesoscale to submesoscale transition in the California Current System. Part I: flow structure, eddy flux, and observational tests. Journal of Physical Oceanography 38, 29-43.

Capet, X., McWilliams, J.C., Molemaker, M.J., Shchepetkin, A.F., 2008b. Mesoscale to submesoscale transition in the California Current System. Part II: fronta processes. Journal of Physical Oceanography 39, 44-64.

Capet, X., McWilliams, J.C., Molemaker, M.J., Shchepetkin, A.F., 2008c. Mesoscale to submesoscale transition in the California Current System. Part III: energy balance and flux. Journal of Physical Oceanography 38, 2256-2269.

Centurioni, L., Ohlmann, J., Niiler, P., 2008. Permanent meanders in the California Current System. Journal of Physical Oceanography 38, 1690-1710.

Chan, F., Barth, J., Lubchenco, J., Kirincich, A., Weeks, H., Peterson, W., Menge, B. 2008. Emergence of anoxia in the California current large marine ecosystem. Science 319, 920.

Chavez, F., Ryan, J., Lluch-Cota, S., Ñiquen, M., 2003. From anchovies to sardines and back: multidecadal change in the Pacific Ocean. Science 299, 217-221.

Chelton, D., Schlax, M., Samelson, R., 2007. Summertime coupling between sea surface temperature and wind stress in the California Current System. Journal of Physical Oceanography 37, 495-517.

Chhak, K., Di Lorenzo, E., 2007. Decadal variations in the California Current upwelling cells. Geophysical Research Letters 34, L14604. doi:10.1029/ 2007GL030203.

Cornuelle, B.D., Chereskin, T.K., Niiler, P., Morris, M.Y., Musgrave, D.L., 2000 Observations and modeling of a California undercurrent eddy. Journal of Geophysical Research 105, 1227-1243.

Cox, M., Bryan, K., 1984. A numerical model of the ventilated thermocline. Journal of Physical Oceanography 14, 674-687.

Davis, R.E., Ohman, M., Rudnick, D., Sherman, J., Hodges, B., 2008. Glider surveillance of physics and biology in the southern California Current System. Limnology and Oceanography 53, 2151-2168.

Di Lorenzo, E., 2003. Seasonal dynamics of the surface circulation in the Southern California Current System. Deep-Sea Research II 50, 2371-2388.

Di Lorenzo, E., Miller, A.J., Schneider, N., McWilliams, J., 2005. The warming of the California Current: dynamics and ecosystem implications. Journal of Physical Oceanography 35, 336-362.

Dong, C., Idica, E., McWilliams, J., 2009. Circulation and multiple scale variability in the Southern California Bight. Progress in Oceanography 82, 168-190.

Douglass, E., Roemmich, D., Stammer, D., 2006. Interannual variability in Northeast Pacific circulation. Journal of Geophysical Research 111, C04001. doi:10.1029/ 2005JC003015

Emery, B., Washburn, L., Harlan, J., 2004. Evaluating radial current measurements from CODAR high-frequency radars with moored current meters. Journal of Atmospheric and Oceanic Technology 21, 1259-1271.

Gan, J., Allen, J.S., 2002. A modeling study of shelf circulation off northern California in the region of the Coastal Ocean Dynamics Experiment: response to relaxation of upwelling winds. Journal of Geophysical Research 107, 3123. doi:10.1029/ 2000JC000768.
Gilson, J., Roemmich, D., Cornuelle, B., 1998. Relationship of TOPEX/Poseidon altimetric steric height and circulation in the North Pacific. Journal of Geophysical Research 103, 27,947-27,965.

Goebel, N., Edwards, C., Zehr, J.P., Follows, M.J., 2010. An emergent community ecosystem model applied to the California Current System. Journal of Marine Systems 83, 221-241.

Hautala, S.L., Roemmich, D.H., 1998. Subtropical mode water in the Northeast Pacific Basin. Journal of Geophysical Research 103, 13055-13066.

Hendy, I.L., Kennett, J.P., 2003. Tropical forcing of North Pacific intermediate water distribution during late Quaternary rapid climate change. Quaternary Science Reviews 22, 673-689.

Hickey, B., 1979. The California Current, hypothesis and facts. Progress in Oceanography 8, 191-279.

Hickey, B., 1998. Coastal oceanography of Western North America from the tip of Baja California to Vancouver Island. The Sea 11, 345-393.

Huyer, A., 1983. Coastal upwelling in the California Current System. Progress in Oceanography 12, 259-284.

Kalnay, E., Kanamitsu, M., Kistler, R., Collins, W., Deaven, D., Gandin, L., Iredell, M., Saha, S., White, G., Woollen, J., Zhu, Y., Chelliah, M., Ebisuzaki, W., Higgins, W., Janowiak, J., Mo, KC., Ropelewski, C., Wang, J., Leetmaa, A., Reynolds, R., Jenne, R., Joseph, D., 1996. The NCEP/NCAR 40-year reanalysis project. Bulletin of the American Meteorological Society 77 (3), 437-471.

Kang, Y., Price, J.M., Magaard, L., 1982. On Stable and unstable Rossby waves in nonzonal oceanic shear flow. Journal of Physical Oceanography 12, 528-537.

Kelly, K., Beardsley, R., Limeburner, R., Brink, K., 1998. Variability of the near-surface eddy kinetic energy in the California Current based on altimetric, drifter and moored data. Journal Geophysical Research 103, 13,067-13,083.

Kennett, J.P., Cannariato, K.G., Hendy, I.L., Behl, R.J., 2003. Methane Hydrates in Quaternary Climate Change: The Clathrate Gun Hypothesis, Special Publications 54. AGU, Washington, DC, $216 \mathrm{pp}$.

Lee, D-K., Niiler, P.P., 1987. The local baroclinic instability of geostrophic spirals in the eastern North Pacific ocean. Journal of Physical Oceanography 17, 13661377.

Levy, M., Klein, P., Treguier, A., Iovino, D., Madec, G., Masson, S., Takahashi, K., 2010. Modification of gyre circulation by sub-mesoscale physics. Ocean Modelling 34, $1-15$.

Logerwell, E.A., Smith, P.E., 2001. Mesoscale eddies and survival of late stage Pacific sardine (Sardinops sagax) larva. Fisheries Oceanography 10, 13-25.

Lynn, R.J., 1967. Seasonal variation of temperature and salinity at 10 meters in the California Current. CalCOFI Report 11, 86-157.

Lynn, R., Simpson, J., 1987. The California Current System: the seasonal variability of its physical properties. Journal of Geophysical Research 92, 12,947-12,966.

Marchesiello, P., Estrade, P., 2009. Eddy activity and mixing in upwelling systems: a comparative study of Northwest Africa and California regions. International Journal of Earth Sciences 98, 299-308.

Marchesiello, P., McWilliams, J.C., Shchepetkin, A., 2003. Equilibrium structure and dynamics of the California Current System. Journal of Physical Oceanography 33, 753-783.

Maximenko, N., Melnichenko, O., Niiler, P.P., Sasaki, H., 2008. Stationary mesoscale jet-like features in the ocean. Geophysical Research Letters 35, L08603. doi:10.1029/2008GL033267.

McClatchie, S., Goericke, R., Koslow, A.J., and 24 other authors, 2008. The State of the California Current, 2007-2008: La Niña conditions and their effects on the ecosystem. CalCOFI Reports 49, 39-76.

McClatchie, S., Goericke, R., Cosgrove, R., Auad, G., Vetter, R., 2010. Oxygen in the Southern California Bight: multidecadal trends and implications for demersal fisheries. Geophysical Research Letters 37, L19602. doi:10.1029/2010GL044497.

McGowan, J., Cayan, D., Dorman, C., 1998. Climate-ocean variability and ecosystem response in the Northeast Pacific. Science 281, 210-217.

McGowan, J., Bograd, S., Lynn, R., Miller, A., 2003. The biological response of the 1977 regime shift in the California Current. Deep-Sea Research 50, 2567-2582.

Miller, A.J., Schneider, N., 2000. Interdecadal climate regime dynamics in the North Pacific Ocean: theories, observations and ecosystem impacts. Progress in Oceanography 47, 355-379.

Montgomery, R., 1937. A suggested method for representing gradient flow in isentropic surfaces. Bulletin of the American Meteorological Society 18, 210212 .

Moore, A., Arango, H., DiLorenzo, E., Miller, A., Cornuelle, B., 2009. An adjoint sensitivity analysis of the Southern California Current circulation and ecosystem. Journal of Physical Oceanography 39, 702-720.

Mysak, L., 1977. On the stability of the California Undercurrent off Vancouver Island. Journal of Physical Oceanography 7, 904-917.

Parés-Sierra, A., O'Brien, J., 1989. The seasonal and interannual variability of the California Current System: a numerical model. Journal of Geophysical Research 93, 3159-3180.

Powell, T.P., Lewis, C.V.W., Curchitser, E.N., Haidvogel, D.B., Hermann, A.J., Dobbins, E.L., 2006. Results from a three-dimensional, nested biological-physical model of the California Current System and comparisons with statistics from satellite imagery. Journal of Geophysical Research 111, C07018. doi:10.1029/ 2004JC002506.

Reid, J.L., 1965. Intermediate waters of the Pacific Ocean. The John Hopkins Oceanographic Studies 2, $85 \mathrm{pp}$.

Reid, J.L., Roden, G., Wyllie, J., 1958. Studies of the California Current System. CalCOFI Progress Report 7-1-56 to 1-1-58, Marine Resources Committee, California Department of Fish and Game, Sacramento, pp. 27-56. 
Roemmich, D., 1989. Mean transport of mass, heat, salt and nutrients in southern California coastal waters: implications for primary production and nutrient cycling. Deep-Sea Research 36, 1359-1378.

Roemmich, D., Gilson, J., 2009. The 2004-2008 mean and annual cycle of temperature, salinity, and steric height in the global ocean from the Argo Program. Progress in Oceanography 82, 81-100.

Roemmich, D., Gilson, J., 2011. The global ocean imprint of ENSO. Geophysical Research Letters 38, L13606. doi:10.1029/2011GL047992.

Roemmich, D., McGowan, J., 1995. Climate warming and the decline of zooplankton in the California Current. Science 267, 1324-1326.

Roemmich, D., Gilson, J., Cornuelle, B., Weller, R., 2001. The mean and time-varying meridional heat transport at the tropical/subtropical boundary of the North Pacific Ocean. Journal of Geophysical Research 106, 8957-8970.

Rykaczewski, R.R., Dunne, J.P., 2010. Enhanced nutrient supply to the California Current Ecosystem with global warming and increased stratification in an earth system model. Geophysical Research Letters 37, L21606. doi:10.1029/ 2010GL045019.

Schneider, N., Di Lorenzo, E., Niiler, P., 2005. Salinity variations in the California Current. Journal of Physical Oceanography 35 (8), 1421-1436.

Schwing, F., Mendelssohn, R., 1997. Increased coastal upwelling in the California Current System. Journal of Geophysical Research 102, 3421-3438.

Schwing, F., Moore, C., Ralston, S., Sakuma, K.A., 2000. Record Coastal Upwelling in the California Current in 1999, CalCOFI Report 41, pp. 148-160.

Seo, H., Miller, A., Roads, J., 2007. The Scripps Coupled Ocean-Atmosphere Regional (SCOAR) model, with applications in the Eastern Pacific Sector. Journal of Climate 20, 381-402.

Snyder, M., Sloan, L., Diffenbaugh, N., Bell, J., 2003. Future climate change and upwelling in the California Current. Geophysical Research Letters 30. doi:10,1029/2003GL017647.

Strub, P.T., James, C., 2000. Altimeter-derived variability of surface velocities in the California Current System: 2. Seasonal circulation and eddy statistics. Deep-Sea Research II 47, 831-870.
Suga, T., Aoki, Y., Saito, H., Hanawa, K., 2008. Ventilation of the North Pacific subtropical pycnocline and mode water formation. Progress in Oceanography 77, 285-297.

Sverdrup, H.U., Johnson, M.W., Fleming, R.H., 1942. The Oceans, Their Physics, Chemistry and General Biology. Prentice Hall, $1087 \mathrm{pp}$.

Sydeman, W.J., Hester, M.M., Thayer, J.A., Gress, F., Martin, P., Buffa, J., 2001. Climate change, reproductive performance, and diet composition of marine birds in the southern California Current system. Progress in Oceanography 49, 309-329.

Talley, L.D., 1988. Potential vorticity distribution in the North Pacific. Journal of Physical Oceanography 18, 89-106.

Talley, L.D., 1993. Distribution of North Pacific intermediate water. Journal of Physical Oceanography 23, 517-537.

Talley, L.D., Roemmich, D., 1991. A tribute to Joe Reid in recognition of 40 years of contributions to oceanography. Deep-Sea Research 38 (Suppl.), vii-viii.

Tibby, R.B., 1939. Report on Returns of Drift Bottles Released off Southern California, 1937, Fish Bulletin 55, Division of Fish and Game, California, Bureau of Marine Fisheries.

Todd, R., Rudnick, D., Mazloff, M., Davis, R., Cornuelle, B., 2011. Poleward flows in the southern California Current System: glider observations and numerica simulation. Journal of Geophysical Research 116 (116), C02026. doi:10.1029/ 2010JC006536.

Tsuchiya, M., 1991. Flow path of Antarctic Intermediate Water in the western equatorial South Pacific Ocean. Deep-Sea Research I 38, S273-S279.

Wilcox-Silver, M., 1975. The habitat of Salpa fusiformis in the California Current as defined by indicator assemblages. Limnology and Oceanography 20, 230-237.

Wyllie, J.G., 1966. Geostrophic flow of the California Current at the surface and at $200 \mathrm{~m}$. CalCOFI Atlas, 13 pp., and 288 charts.

Zhong, Y., Liu, Z., 2009. On the mechanism of pacific multidecadal climate variability in CCSM3: the role of the subpolar North Pacific ocean. Journal of Physical Oceanography 39, 2052-2076. 